\title{
Generalized mixed equilibria, variational inequalities and constrained convex minimization
}

\author{
Lu-Chuan Ceng ${ }^{\mathrm{a}}$, Ching-Feng Wen ${ }^{\mathrm{b}, \mathrm{c}, *}$ \\ a Department of Mathematics, Shanghai Normal University, and Scientific Computing Key Laboratory of Shanghai Universities, \\ Shanghai 200234, China. \\ ${ }^{b}$ Center for Fundamental Science, and Research Center for Nonlinear Analysis and Optimization, Kaohsiung Medical University, \\ Kaohsiung 807, Taiwan.
}

${ }^{c}$ Department of Medical Research, Kaohsiung Medical University Hospital, Kaohsiung 807, Taiwan.

Communicated by X. Qin

\begin{abstract}
In this paper, we introduce one multistep relaxed implicit extragradient-like scheme and another multistep relaxed explicit extragradient-like scheme for finding a common element of the set of solutions of the minimization problem for a convex and continuously Fréchet differentiable functional, the set of solutions of a finite family of generalized mixed equilibrium problems and the set of solutions of a finite family of variational inequalities for inverse strongly monotone mappings in a real Hilbert space. Under suitable control conditions, we establish the strong convergence of these two multistep relaxed extragradient-like schemes to the same common element of the above three sets, which is also the unique solution of a variational inequality defined over the intersection of the above three sets. (c)2017 All rights reserved.
\end{abstract}

Keywords: Convex minimization problem, generalized mixed equilibrium problem, variational inequality, inverse-strongly monotone mapping.

2010 MSC: 49J30, 47H09, 47J20, 49M05.

\section{Introduction}

Let $\mathrm{H}$ be a real Hilbert space with inner product $\langle\cdot, \cdot\rangle$ and norm $\|\cdot\|, \mathrm{C}$ be a nonempty closed convex subset of $\mathrm{H}$ and $\mathrm{P}_{\mathrm{C}}$ be the metric projection of $\mathrm{H}$ onto $\mathrm{C}$. Let $\mathrm{T}: \mathrm{C} \rightarrow \mathrm{C}$ be a self-mapping on $\mathrm{C}$. We denote by $\operatorname{Fix}(T)$ the set of fixed points of $T$ and by $\mathbf{R}$ the set of all real numbers. A mapping $A: H \rightarrow H$ is called $\bar{\gamma}$-strongly positive on $\mathrm{H}$, if there exists a constant $\bar{\gamma}>0$ such that

$$
\langle A x, x\rangle \geqslant \bar{\gamma}\|x\|^{2}, \quad \forall x \in H .
$$

A mapping $\mathrm{F}: \mathrm{C} \rightarrow \mathrm{H}$ is called L-Lipschitz continuous, if there exists a constant $\mathrm{L} \geqslant 0$ such that

$$
\|\mathrm{F} x-\mathrm{Fy}\| \leqslant \mathrm{L}\|x-y\|, \quad \forall x, y \in C .
$$

\footnotetext{
*Corresponding author

Email addresses: zenglc@hotmail .com (Lu-Chuan Ceng), cfwen@kmu .edu.tw (Ching-Feng Wen) doi:10.22436/jnsa.010.02.39
} 
In particular, if $L=1$ then $F$ is called a nonexpansive mapping, if $L \in[0,1)$ then $F$ is called a contraction. A mapping $\mathrm{T}: \mathrm{C} \rightarrow \mathrm{C}$ is called $\mathrm{k}$-strictly pseudocontractive (or a $\mathrm{k}$-strict pseudocontraction), if there exists a constant $k \in[0,1)$ such that

$$
\|T x-T y\|^{2} \leqslant\|x-y\|^{2}+k\|(I-T) x-(I-T) y\|^{2}, \quad \forall x, y \in C .
$$

In particular, if $k=0$, then $T$ is a nonexpansive mapping. The mapping $T$ is pseudocontractive, if and only if

$$
\langle T x-T y, x-y\rangle \leqslant\|x-y\|^{2}, \quad \forall x, y \in C .
$$

$\mathrm{T}$ is strongly pseudocontractive, if and only if there exists a constant $\lambda \in(0,1)$ such that

$$
\langle T x-T y, x-y\rangle \leqslant \lambda\|x-y\|^{2}, \quad \forall x, y \in C .
$$

Let $\mathcal{A}: \mathrm{C} \rightarrow \mathrm{H}$ be a nonlinear mapping on $\mathrm{C}$. The variational inequality problem (VIP) associated with the set $\mathrm{C}$ and the mapping $\mathcal{A}$ is stated as follows: find $x^{*} \in \mathrm{C}$ such that

$$
\left\langle\mathcal{A} x^{*}, x-x^{*}\right\rangle \geqslant 0, \quad \forall x \in C .
$$

The solution set of VIP $(1.1)$ is denoted by $\operatorname{VI}(C, \mathcal{A})$.

There are many applications of VIP (1.1) in various fields. In 1976, Korpelevich [18] proposed an iterative algorithm for solving VIP (1.1) in Euclidean space $\mathbf{R}^{\mathrm{n}}$ :

$$
\left\{\begin{array}{l}
y_{n}=P_{C}\left(x_{n}-\tau \mathcal{A} x_{n}\right), \\
x_{n+1}=P_{C}\left(x_{n}-\tau \mathcal{A} y_{n}\right), \quad \forall n \geqslant 0,
\end{array}\right.
$$

with $\tau>0$ a given number, which is known as the extragradient method. The literature on the VIP is vast and Korpelevich's extragradient method has received great attention given by many authors, who improved it in various ways; see e.g., $[7-9,11,13,15,21]$ and references therein.

On the other hand, let $\varphi: \mathrm{C} \rightarrow \mathbf{R}$ be a real-valued function, $\mathcal{A}: \mathrm{C} \rightarrow \mathrm{H}$ be a nonlinear mapping and $\Theta: \mathbf{C} \times \mathbf{C} \rightarrow \mathbf{R}$ be a bifunction. In 2008, Peng and Yao [21] introduced the following generalized mixed equilibrium problem (GMEP) of finding $x \in C$ such that

$$
\Theta(x, y)+\varphi(y)-\varphi(x)+\langle\mathcal{A} x, y-x\rangle \geqslant 0, \quad \forall y \in C .
$$

We denote the set of solutions of $\operatorname{GMEP}(1.2)$ by $\operatorname{GMEP}(\Theta, \varphi, \mathcal{A})$. The $\operatorname{GMEP}(1.2)$ is very general in the sense that it includes, as special cases, optimization problems, variational inequalities, minimax problems, Nash equilibrium problems in noncooperative games and others. The GMEP (1.2) contains GEP [8], MEP [14] and EP [27] as particular cases.

It was assumed in [21] that $\Theta: C \times C \rightarrow \mathbf{R}$ is a bifunction satisfying conditions (A1)-(A4) and $\varphi: C \rightarrow \mathbf{R}$ is a lower semicontinuous and convex function with restriction (B1) or (B2), where

(A1) $\Theta(x, x)=0$, for all $x \in C$;

(A2) $\Theta$ is monotone, i.e., $\Theta(x, y)+\Theta(y, x) \leqslant 0$, for any $x, y \in C$;

(A3) $\Theta$ is upper-hemicontinuous, i.e., for each $x, y, z \in C$,

$$
\limsup _{t \rightarrow 0^{+}} \Theta(t z+(1-t) x, y) \leqslant \Theta(x, y)
$$

(A4) $\Theta(x, \cdot)$ is convex and lower semicontinuous for each $x \in C$;

(B1) for each $x \in H$ and $r>0$, there exists a bounded subset $D_{x} \subset C$ and $y_{x} \in C$ such that for any $z \in C \backslash D_{x}$,

$$
\Theta\left(z, y_{x}\right)+\varphi\left(y_{x}\right)-\varphi(z)+\frac{1}{r}\left\langle y_{x}-z, z-x\right\rangle<0
$$

(B2) $\mathrm{C}$ is a bounded set. 
Given a positive number $r>0$, let $T_{r}^{(\Theta, \varphi)}: H \rightarrow C$ be the solution set of the auxiliary mixed equilibrium problem, that is, for each $x \in H$,

$$
\mathrm{T}_{r}^{(\Theta, \varphi)}(x):=\left\{y \in C: \Theta(y, z)+\varphi(z)-\varphi(y)+\frac{1}{r}\langle y-x, z-y\rangle \geqslant 0, \forall z \in C\right\} .
$$

In particular, if $\varphi \equiv 0$ then $\mathrm{T}_{\mathrm{r}}^{(\Theta, \varphi)}$ is rewritten as $\mathrm{T}_{\mathrm{r}}^{\Theta}: \mathrm{H} \rightarrow \mathrm{C}$, i.e.,

$$
\mathrm{T}_{\mathrm{r}}^{\Theta}(x):=\left\{y \in C: \Theta(y, z)+\frac{1}{\mathrm{r}}\langle y-x, z-y\rangle \geqslant 0, \forall z \in C\right\} .
$$

Furthermore, let $\mathrm{f}: \mathrm{C} \rightarrow \mathbf{R}$ be a convex and continuously Fréchet differentiable functional. Consider the convex minimization problem (CMP) of minimizing $f$ over the constraint set $C$

$$
\operatorname{minf}_{x \in C}(x)
$$

(assuming the existence of minimizers). We denote by $\Xi$ the set of minimizers of CMP (1.3).

Motivated and inspired by the above facts, we introduce one multistep relaxed implicit extragradientlike scheme and another multistep relaxed explicit extragradient-like scheme for finding a common element of the set of solutions of the CMP (1.3) for a convex functional $f: C \rightarrow \mathbf{R}$ with L-Lipschitz continuous gradient $\nabla f$, the set of solutions of a finite family of GMEPs and the set of solutions of a finite family of variational inequalities for inverse-strongly monotone mappings in a real Hilbert space. Under suitable control conditions, we establish the strong convergence of these two multistep relaxed extragradient-like schemes to the same common element of the above three sets, which is also the unique solution of a variational inequality defined over the intersection of the above three sets. We also refer readers to [1$3,5,6,12,16]$ and references therein for some more related papers published recently.

\section{Preliminaries}

Throughout this paper, we assume that $\mathrm{H}$ is a real Hilbert space whose inner product and norm are denoted by $\langle\cdot, \cdot\rangle$ and $\|\cdot\|$, respectively. Let $C$ be a nonempty closed convex subset of $H$. We write $x_{n} \rightarrow x$ to indicate that the sequence $\left\{x_{n}\right\}$ converges weakly to $x$ and $x_{n} \rightarrow x$ to indicate that the sequence $\left\{x_{n}\right\}$ converges strongly to $x$. Moreover, we use $\omega_{w}\left(x_{n}\right)$ to denote the weak $\omega$-limit set of the sequence $\left\{x_{n}\right\}$, i.e.,

$$
\omega_{w}\left(x_{n}\right):=\left\{x \in H: x_{n_{i}} \rightarrow x \text { for some subsequence }\left\{x_{n_{i}}\right\} \text { of }\left\{x_{n}\right\}\right\} .
$$

The metric (or nearest point) projection from $\mathrm{H}$ onto $\mathrm{C}$ is the mapping $\mathrm{P}_{\mathrm{C}}: \mathrm{H} \rightarrow \mathrm{C}$ which assigns to each point $x \in H$ the unique point $P_{C} x \in C$ satisfying the property

$$
\left\|x-P_{C} x\right\|=\inf _{y \in C}\|x-y\|=: d(x, C) .
$$

The following properties of projections are useful and pertinent to our purpose.

Proposition 2.1. Given any $\mathrm{x} \in \mathrm{H}$ and $z \in \mathrm{C}$, one has

(i) $z=\mathrm{P}_{\mathrm{C}} \mathrm{x} \Leftrightarrow\langle x-z, y-z\rangle \leqslant 0, \forall y \in \mathrm{C}$;

(ii) $z=\mathrm{P}_{\mathrm{C}} \mathrm{x} \Leftrightarrow\|x-z\|^{2} \leqslant\|x-y\|^{2}-\|y-z\|^{2}, \forall y \in C$;

(iii) $\left\langle\mathrm{P}_{\mathrm{C}} \mathrm{x}-\mathrm{P}_{\mathrm{C}} \mathrm{y}, \mathrm{x}-\mathrm{y}\right\rangle \geqslant\left\|\mathrm{P}_{\mathrm{C}} \mathrm{x}-\mathrm{P}_{\mathrm{C}} \mathrm{y}\right\|^{2}, \forall \mathrm{y} \in \mathrm{H}$, which hence implies that $\mathrm{P}_{\mathrm{C}}$ is nonexpansive and monotone.

Definition 2.2. A mapping $\mathrm{T}: \mathrm{H} \rightarrow \mathrm{H}$ is said to be firmly nonexpansive, if $2 \mathrm{~T}-\mathrm{I}$ is nonexpansive, or equivalently if $\mathrm{T}$ is 1-inverse strongly monotone (1-ism),

$$
\langle x-y, T x-T y\rangle \geqslant\|T x-T y\|^{2}, \quad \forall x, y \in H,
$$

alternatively, $\mathrm{T}$ is firmly nonexpansive, if and only if $\mathrm{T}$ can be expressed as 


$$
\mathrm{T}=\frac{1}{2}(\mathrm{I}+\mathrm{S}),
$$

where $\mathrm{S}: \mathrm{H} \rightarrow \mathrm{H}$ is nonexpansive, projections are firmly nonexpansive.

Definition 2.3. A mapping $\mathrm{F}: \mathrm{C} \rightarrow \mathrm{H}$ is said to be

(i) monotone, if

$$
\langle F x-F y, x-y\rangle \geqslant 0, \quad \forall x, y \in C ;
$$

(ii) $\eta$-strongly monotone, if there exists a constant $\eta>0$ such that

$$
\langle F x-F y, x-y\rangle \geqslant \eta\|x-y\|^{2}, \quad \forall x, y \in C ;
$$

(iii) $\alpha$-inverse-strongly monotone, if there exists a constant $\alpha>0$ such that

$$
\langle F x-F y, x-y\rangle \geqslant \alpha\|F x-F y\|^{2}, \quad \forall x, y \in C .
$$

It can be easily seen that if $\mathrm{T}$ is nonexpansive, then $\mathrm{I}-\mathrm{T}$ is monotone. It is also easy to see that the projection $\mathrm{P}_{\mathrm{C}}$ is 1-ism. Inverse strongly monotone (also referred to as co-coercive) operators have been applied widely in solving practical problems in various fields.

On the other hand, it is obvious that if $\mathrm{F}: \mathrm{C} \rightarrow \mathrm{H}$ is $\alpha$-inverse-strongly monotone, then $\mathrm{F}$ is monotone and $\frac{1}{\alpha}$-Lipschitz continuous. Moreover, we also have that, for all $u, v \in C$ and $\lambda>0$,

$$
\|(I-\lambda F) u-(I-\lambda F) v\|^{2} \leqslant\|u-v\|^{2}+\lambda(\lambda-2 \alpha)\|F u-F v\|^{2} .
$$

So, if $\lambda \leqslant 2 \alpha$, then $I-\lambda F$ is a nonexpansive mapping from $C$ to $H$.

Next we list some elementary conclusions for the MEP whose solution is denoted by $\operatorname{MEP}(\Theta, \varphi)$.

Proposition 2.4 ([14]). Assume that $\Theta: \mathrm{C} \times \mathrm{C} \rightarrow \mathbf{R}$ satisfies (A1)-(A4) and let $\varphi: \mathrm{C} \rightarrow \mathbf{R}$ be a proper lower semicontinuous and convex function. Assume that either (B1) or (B2) holds. For $\mathrm{r}>0$ and $\mathrm{x} \in \mathrm{H}$, define a mapping $\mathrm{T}_{\mathrm{r}}^{(\Theta, \varphi)}: \mathrm{H} \rightarrow \mathrm{C}$ as follows:

$$
\mathrm{T}_{\mathrm{r}}^{(\Theta, \varphi)}(\mathrm{x})=\left\{z \in \mathrm{C}: \Theta(z, y)+\varphi(y)-\varphi(z)+\frac{1}{\mathrm{r}}\langle\mathrm{y}-z, z-x\rangle \geqslant 0, \forall y \in C\right\},
$$

for all $\mathrm{x} \in \mathrm{H}$. Then the following hold:

(i) for each $\mathrm{x} \in \mathrm{H}, \mathrm{T}_{\mathrm{r}}^{(\Theta, \varphi)}(\mathrm{x})$ is nonempty and single-valued;

(ii) $\mathrm{T}_{\mathrm{r}}^{(\Theta, \varphi)}$ is firmly nonexpansive, that is, for any $\mathrm{x}, \mathrm{y} \in \mathrm{H}$,

$$
\left\|T_{r}^{(\Theta, \varphi)} x-T_{r}^{(\Theta, \varphi)} y\right\|^{2} \leqslant\left\langle T_{r}^{(\Theta, \varphi)} x-T_{r}^{(\Theta, \varphi)} y, x-y\right\rangle ;
$$

(iii) $\operatorname{Fix}\left(\mathrm{T}_{r}^{(\Theta, \varphi)}\right)=\operatorname{MEP}(\Theta, \varphi)$;

(iv) $\operatorname{MEP}(\Theta, \varphi)$ is closed and convex;

(v) $\left\|T_{s}^{(\Theta, \varphi)} \chi-T_{t}^{(\Theta, \varphi)} \chi\right\|^{2} \leqslant \frac{s-t}{s}\left\langle T_{s}^{(\Theta, \varphi)} \chi-T_{t}^{(\Theta, \varphi)} \chi, T_{s}^{(\Theta, \varphi)} \chi-\chi\right\rangle$, for all $s, t>0$ and $x \in H$.

Definition 2.5. A mapping $\mathrm{T}: \mathrm{H} \rightarrow \mathrm{H}$ is said to be an averaged mapping, if it can be written as the average of the identity I and a nonexpansive mapping, that is,

$$
\mathrm{T} \equiv(1-\alpha) \mathrm{I}+\alpha \mathrm{S},
$$

where $\alpha \in(0,1)$ and $S: H \rightarrow H$ is nonexpansive. More precisely, when the last equality holds, we say that $\mathrm{T}$ is $\alpha$-averaged. Thus firmly nonexpansive mappings (in particular, projections) are $\frac{1}{2}$-averaged mappings. 
Definition 2.6 ([4]). Let $\mathrm{S}, \mathrm{T}, \mathrm{V}: \mathrm{H} \rightarrow \mathrm{H}$ be given operators.

(i) If $T=(1-\alpha) S+\alpha V$ for some $\alpha \in(0,1)$ and if $S$ is averaged and $V$ is nonexpansive, then $T$ is averaged.

(ii) $\mathrm{T}$ is firmly nonexpansive, if and only if the complement $\mathrm{I}-\mathrm{T}$ is firmly nonexpansive.

(iii) If $T=(1-\alpha) S+\alpha V$ for some $\alpha \in(0,1)$ and if $S$ is firmly nonexpansive and $V$ is nonexpansive, then $\mathrm{T}$ is averaged.

(iv) The composite of finitely many averaged mappings is averaged. That is, if each of the mappings $\left\{T_{i}\right\}_{i=1}^{N}$ is averaged, then so is the composite $T_{1} \cdots T_{N}$. In particular, if $T_{1}$ is $\alpha_{1}$-averaged and $T_{2}$ is $\alpha_{2}$-averaged, where $\alpha_{1}, \alpha_{2} \in(0,1)$, then the composite $T_{1} T_{2}$ is $\alpha$-averaged, where $\alpha=\alpha_{1}+\alpha_{2}-\alpha_{1} \alpha_{2}$.

(v) If the mappings $\left\{T_{i}\right\}_{i=1}^{N}$ are averaged and have a common fixed point, then

$$
\bigcap_{i=1}^{N} \operatorname{Fix}\left(T_{i}\right)=\operatorname{Fix}\left(T_{1} \cdots T_{N}\right) .
$$

The notation $\operatorname{Fix}(T)$ denotes the set of all fixed points of the mapping $T$, that is, $\operatorname{Fix}(T)=\{x \in H$ : $\mathrm{T} x=x\}$.

We need some facts and tools in a real Hilbert space $\mathrm{H}$ which are listed as lemmas below.

Lemma 2.7. Let $\mathrm{X}$ be a real inner product space. Then there holds the following inequality

$$
\|x+y\|^{2} \leqslant\|x\|^{2}+2\langle y, x+y\rangle, \quad \forall x, y \in X
$$

Lemma 2.8. Let $\mathrm{H}$ be a real Hilbert space. Then the following hold:

(a) $\|x-y\|^{2}=\|x\|^{2}-\|y\|^{2}-2\langle x-y, y\rangle$, for all $x, y \in H$;

(b) $\|\lambda x+\mu y\|^{2}=\lambda\|x\|^{2}+\mu\|y\|^{2}-\lambda \mu\|x-y\|^{2}$, for all $x, y \in H$ and $\lambda, \mu \in[0,1]$ with $\lambda+\mu=1$;

(c) If $\left\{x_{\mathrm{n}}\right\}$ is a sequence in $\mathrm{H}$ such that $\mathrm{x}_{\mathrm{n}} \rightarrow \mathrm{x}$, it follows that

$$
\limsup _{n \rightarrow \infty}\left\|x_{n}-y\right\|^{2}=\limsup _{n \rightarrow \infty}\left\|x_{n}-x\right\|^{2}+\|x-y\|^{2}, \quad \forall y \in H .
$$

It is clear that, in a real Hilbert space $\mathrm{H}, \mathrm{T}: \mathrm{C} \rightarrow \mathrm{C}$ is k-strictly pseudocontractive, if and only if the following inequality holds:

$$
\langle\mathrm{T} x-\mathrm{T} y, x-y\rangle \leqslant\|x-y\|^{2}-\frac{1-k}{2}\|(I-T) x-(I-T) y\|^{2}, \quad \forall x, y \in C .
$$

Lemma 2.9 ([20, Proposition 2.1]). Let $\mathrm{C}$ be a nonempty closed convex subset of a real Hilbert space $\mathrm{H}$ and $\mathrm{T}: \mathrm{C} \rightarrow \mathrm{C}$ be a mapping.

(i) If $\mathrm{T}$ is a $\mathrm{k}$-strictly pseudocontractive mapping, then $\mathrm{T}$ satisfies the Lipschitzian condition

$$
\|T x-T y\| \leqslant \frac{1+k}{1-k}\|x-y\|, \quad \forall x, y \in C .
$$

(ii) If $\mathrm{T}$ is a k-strictly pseudocontractive mapping, then the mapping $\mathrm{I}-\mathrm{T}$ is semiclosed at 0 , that is, if $\left\{x_{\mathrm{n}}\right\}$ is a sequence in $\mathrm{C}$ such that $\mathrm{x}_{\mathrm{n}} \rightarrow \tilde{\mathrm{x}}$ and $(\mathrm{I}-\mathrm{T}) \mathrm{x}_{\mathrm{n}} \rightarrow 0$, then $(\mathrm{I}-\mathrm{T}) \tilde{\mathrm{x}}=0$.

(iii) If $\mathrm{T}$ is $\mathrm{k}$-(quasi-)strict pseudocontraction, then the fixed-point set $\operatorname{Fix}(\mathrm{T})$ of $\mathrm{T}$ is closed and convex so that the projection $\mathrm{P}_{\mathrm{Fix}(\mathrm{T})}$ is well-defined. 
Lemma 2.10 ([26]). Let $\mathrm{C}$ be a nonempty closed convex subset of a real Hilbert space $\mathrm{H}$. Let $\mathrm{T}: \mathrm{C} \rightarrow \mathrm{C}$ be a $\mathrm{k}$-strictly pseudocontractive mapping. Let $\gamma$ and $\delta$ be two nonnegative real numbers such that $(\gamma+\delta) \mathrm{k} \leqslant \gamma$. Then

$$
\|\gamma(x-y)+\delta(T x-T y)\| \leqslant(\gamma+\delta)\|x-y\|, \quad \forall x, y \in C .
$$

Lemma 2.11 ([17, Demiclosedness principle]). Let $\mathrm{C}$ be a nonempty closed convex subset of a real Hilbert space $\mathrm{H}$. Let $\mathrm{S}$ be a nonexpansive self-mapping on $\mathrm{C}$. Then $\mathrm{I}-\mathrm{S}$ is demiclosed. That is, whenever $\left\{\mathrm{x}_{\mathrm{n}}\right\}$ is a sequence in $\mathrm{C}$ weakly converging to some $\mathrm{x} \in \mathrm{C}$ and the sequence $\left\{(\mathrm{I}-\mathrm{S}) \mathrm{x}_{\mathrm{n}}\right\}$ strongly converges to some $\mathrm{y}$, it follows that $(\mathrm{I}-\mathrm{S}) \mathrm{x}=\mathrm{y}$. Here $\mathrm{I}$ is the identity operator of $\mathrm{H}$.

Lemma 2.12. Let $\mathcal{A}: \mathrm{C} \rightarrow \mathrm{H}$ be a monotone mapping. In the context of the variational inequality problem the characterization of the projection (see Proposition 2.1 (i)) implies

$$
u \in \operatorname{VI}(C, \mathcal{A}) \Leftrightarrow u=\mathrm{P}_{\mathrm{C}}(\mathrm{u}-\lambda \mathcal{A} u), \quad \lambda>0 .
$$

Let $\mathrm{C}$ be a nonempty closed convex subset of a real Hilbert space $\mathrm{H}$. We introduce some notations. Let $\lambda$ be a number in $(0,1]$ and let $\mu>0$. Associating with a nonexpansive mapping $T: C \rightarrow C$, we define the mapping $\mathrm{T}^{\lambda}: \mathrm{C} \rightarrow \mathrm{H}$ by

$$
\mathrm{T}^{\lambda} x:=\mathrm{T} x-\lambda \mu \mathrm{F}(\mathrm{T} x), \quad \forall x \in \mathrm{C},
$$

where $\mathrm{F}: \mathrm{C} \rightarrow \mathrm{H}$ is an operator such that, for some positive constants $\kappa, \eta>0, F$ is $k$-Lipschitzian and $\eta$-strongly monotone on $\mathrm{C}$, that is, $\mathrm{F}$ satisfies the conditions:

$$
\|F x-F y\| \leqslant k\|x-y\|, \quad \text { and } \quad\langle F x-F y, x-y\rangle \geqslant \eta\|x-y\|^{2},
$$

for all $x, y \in C$.

Lemma 2.13 ([25, Lemma 3.1]). $T^{\lambda}$ is a contraction provided $0<\mu<\frac{2 \eta}{\kappa^{2}}$, that is,

$$
\left\|T^{\lambda} x-T^{\lambda} y\right\| \leqslant(1-\lambda \tau)\|x-y\|, \quad \forall x, y \in C,
$$

where $\tau=1-\sqrt{1-\mu\left(2 \eta-\mu \kappa^{2}\right)} \in(0,1]$.

Lemma 2.14 ([24, Lemma 2.1]). Let $\left\{\mathrm{a}_{\mathrm{n}}\right\}$ be a sequence of nonnegative real numbers satisfying

$$
a_{n+1} \leqslant\left(1-\omega_{n}\right) a_{n}+w_{n} \delta_{n}+r_{n}, \quad \forall n \geqslant 0,
$$

where $\left\{\omega_{n}\right\},\left\{\delta_{n}\right\}$ and $\left\{r_{n}\right\}$ satisfy the following conditions:

(i) $\left\{\omega_{n}\right\} \subset[0,1]$ and $\sum_{n=0}^{\infty} \omega_{n}=\infty$;

(ii) either $\lim \sup _{n \rightarrow \infty} \delta_{n} \leqslant 0$ or $\sum_{n=0}^{\infty} \omega_{n}\left|\delta_{n}\right|<\infty$;

(iii) $r_{n} \geqslant 0$ for all $n \geqslant 0$, and $\sum_{n=1}^{\infty} r_{n}<\infty$.

Then, $\lim _{\mathfrak{n} \rightarrow \infty} a_{\mathfrak{n}}=0$.

Lemma 2.15 ([19]). Assume that $\mathrm{A}$ is a $\bar{\gamma}$-strongly positive bounded linear operator on $\mathrm{H}$ with $0<\rho \leqslant\|\mathrm{A}\|^{-1}$. Then $\|\mathrm{I}-\rho A\| \leqslant 1-\rho \bar{\gamma}$.

Let LIM be a Banach limit. According to time and circumstances, we use $\operatorname{LIM}_{n} a_{n}$ instead of LIMa for every $a=\left\{a_{n}\right\} \in l^{\infty}$. The following properties are well-known:

(i) for all $n \geqslant 1, a_{n} \leqslant c_{n}$ implies $\operatorname{LIM}_{n} a_{n} \leqslant \operatorname{LIM}_{n} c_{n}$;

(ii) $\operatorname{LIM}_{n} a_{n+N}=\operatorname{LIM}_{n} a_{n}$ for any fixed positive integer $N$;

(iii) $\liminf _{n \rightarrow \infty} a_{n} \leqslant \operatorname{LIM}_{n} a_{n} \leqslant \limsup _{n \rightarrow \infty} a_{n}$ for all $\left\{a_{n}\right\} \in l^{\infty}$. 
The following lemma was given in [23, Proposition 2].

Lemma 2.16. Let $a \in \mathbf{R}$ be a real number and let a sequence $\left\{a_{n}\right\} \in l^{\infty}$ satisfy the condition $\operatorname{LIM}_{n} a_{n} \leqslant a$ for all Banach limit LIM. If $\lim \sup _{n \rightarrow \infty}\left(a_{n+1}-a_{n}\right) \leqslant 0$, then $\limsup _{n \rightarrow \infty} a_{n} \leqslant a$.

Recall that a set-valued mapping $\widetilde{T}: D(\widetilde{T}) \subset H \rightarrow 2^{H}$ is called monotone, if for all $x, y \in D(\widetilde{T}), f \in \widetilde{T} x$ and $g \in \widetilde{T} y$ imply

$$
\langle f-g, x-y\rangle \geqslant 0 \text {. }
$$

A set-valued mapping $\widetilde{T}$ is called maximal monotone, if $\widetilde{T}$ is monotone and $(I+\lambda \widetilde{T}) D(\widetilde{T})=H$ for each $\lambda>0$, where $\mathrm{I}$ is the identity mapping of $\mathrm{H}$. We denote by $\mathrm{G}(\widetilde{\mathrm{T}})$ the graph of $\widetilde{T}$. It is known that a monotone mapping $\widetilde{T}$ is maximal, if and only if for $(x, f) \in H \times H,\langle f-g, x-y\rangle \geqslant 0$ for every $(y, g) \in G(\widetilde{T})$ implies $\mathrm{f} \in \widetilde{\mathrm{T}} x$. Next we provide an example to illustrate the concept of maximal monotone mapping.

Let $\mathcal{A}: \mathrm{C} \rightarrow \mathrm{H}$ be a monotone and Lipschitz-continuous mapping and let $\mathrm{N}_{\mathrm{C}} v$ be the normal cone to $\mathrm{C}$ at $v \in \mathrm{C}$, i.e.,

$$
\mathrm{N}_{\mathrm{C}} v=\{\mathrm{u} \in \mathrm{H}:\langle v-p, \mathrm{u}\rangle \geqslant 0, \forall p \in C\}
$$

Define

$$
\widetilde{\mathrm{T}} v= \begin{cases}\mathcal{A} v+\mathrm{N}_{C} v, & \text { if } v \in \mathrm{C} \\ \emptyset, & \text { if } v \notin \mathrm{C}\end{cases}
$$

Then, it is known in [22] that $\widetilde{T}$ is maximal monotone and $0 \in \widetilde{\mathrm{T}} \nu$ if and only if $\nu \in \operatorname{VI}(C, \mathcal{A})$.

\section{Main results}

Let $C$ be a nonempty closed convex subset of a real Hilbert space $H$ and let $M, N$ be two integers. Throughout this section, we always assume the following:

- $\mathrm{F}: \mathrm{C} \rightarrow \mathrm{H}$ is a $\mathrm{k}$-Lipschitzian and $\eta$-strongly monotone operator with positive constants $\mathrm{k}, \eta>0$, and $f: C \rightarrow R$ is a convex functional with L-Lipschitz continuous gradient $\nabla f$;

- $A_{i}: C \rightarrow H$ is $\eta_{i}$-inverse strongly monotone for each $i=1, \cdots, N$, and $B_{j}: C \rightarrow H$ is $\mu_{j}$-inverse strongly monotone for each $j=1, \cdots, M$;

- $\mathrm{A}$ is a $\bar{\gamma}$-strongly positive bounded linear operator on $\mathrm{H}$ with $\bar{\gamma} \in(1,2)$ and $\mathrm{V}: \mathrm{C} \rightarrow \mathrm{H}$ is an $l$-Lipschitzian mapping with $l \geqslant 0$;

- $\Theta_{j}: \mathbf{C} \times \mathbf{C} \rightarrow \mathbf{R}$ is a bifunction satisfying conditions (A1)-(A4) and $\varphi_{j}: \mathbf{C} \rightarrow \mathbf{R} \cup\{+\infty\}$ is a proper lower semicontinuous and convex function with restrictions (B1) or (B2) for each $j=1, \cdots, M$;

- $0<\mu<\frac{2 \eta}{\kappa^{2}}$ and $0 \leqslant \gamma l<\tau$ with $\tau=1-\sqrt{1-\mu\left(2 \eta-\mu \kappa^{2}\right)}$;

- $P_{C}\left(I-\lambda_{t} \nabla f\right)=s_{t} I+\left(1-s_{t}\right) T_{t}$, where $T_{t}$ is nonexpansive, $s_{t}=\frac{2-\lambda_{t} L}{4} \in\left(0, \frac{1}{2}\right)$ and $\lambda_{t}:(0,1) \rightarrow\left(0, \frac{2}{L}\right)$ with $\lim _{\mathrm{t} \rightarrow 0} \lambda_{\mathrm{t}}=\frac{2}{\mathrm{~L}}$;

- $P_{C}\left(I-\lambda_{n} \nabla f\right)=s_{n} I+\left(1-s_{n}\right) T_{n}$, where $T_{n}$ is nonexpansive, $s_{n}=\frac{2-\lambda_{n} L}{4} \in\left(0, \frac{1}{2}\right)$ and $\left\{\lambda_{n}\right\} \subset\left(0, \frac{2}{L}\right)$ with $\lim _{n \rightarrow \infty} \lambda_{n}=\frac{2}{\mathrm{~L}}$;

- $\Lambda_{\mathrm{t}}^{\mathrm{N}}: \mathrm{C} \rightarrow \mathrm{C}$ is a mapping defined by $\Lambda_{\mathrm{t}}^{\mathrm{N}} \mathrm{x}=\mathrm{P}_{\mathrm{C}}\left(\mathrm{I}-\lambda_{\mathrm{N}, \mathrm{t}} A_{\mathrm{N}}\right) \cdots \mathrm{P}_{\mathrm{C}}\left(\mathrm{I}-\lambda_{1, \mathrm{t}} A_{1}\right) \mathrm{x}, \mathrm{t} \in(0,1)$, for $\left\{\lambda_{i, t}\right\} \subset\left[a_{i}, b_{i}\right] \subset\left(0,2 \eta_{i}\right), i=1, \cdots, N$;

- $\Lambda_{n}^{N}: C \rightarrow C$ is a mapping defined by $\Lambda_{n}^{N} x=P_{C}\left(I-\lambda_{N, n} A_{N}\right) \cdots P_{C}\left(I-\lambda_{1, n} A_{1}\right) x$ with $\left\{\lambda_{i, n}\right\} \subset$ $\left[a_{i}, b_{i}\right] \subset\left(0,2 \eta_{i}\right)$ and $\lim _{n \rightarrow \infty} \lambda_{i, n}=\lambda_{i}$, for each $i=1, \cdots, N$;

- $\Delta_{\mathrm{t}}^{\mathrm{M}}: \mathrm{C} \rightarrow \mathrm{C}$ is a mapping defined by $\Delta_{\mathrm{t}}^{\mathrm{M}} \mathrm{x}=\mathrm{T}_{\mathrm{r}_{M, \mathrm{t}}}^{\left(\Theta_{M}, \varphi_{M}\right)}\left(\mathrm{I}-\mathrm{r}_{M, t} \mathrm{~B}_{M}\right) \cdots \mathrm{T}_{\mathrm{r}_{1, \mathrm{t}}}^{\left(\Theta_{1}, \varphi_{1}\right)}\left(\mathrm{I}-\mathrm{r}_{1, \mathrm{t}} \mathrm{B}_{1}\right) \mathrm{x}, \mathrm{t} \in$ $(0,1)$, for $\left\{r_{j, t}\right\} \subset\left[c_{j}, d_{j}\right] \subset\left(0,2 \mu_{j}\right), j=1, \cdots, M$; 
- $\Delta_{\mathfrak{n}}^{M}: C \rightarrow C$ is a mapping defined by $\Delta_{n}^{M} x=T_{r_{M, n}}^{\left(\Theta_{M}, \varphi_{M}\right)}\left(I-r_{M, n} B_{M}\right) \cdots T_{r_{1, n}}^{\left(\Theta_{1,} \varphi_{1}\right)}\left(I-r_{1, n} B_{1}\right) x$ with $\left\{r_{j, n}\right\} \subset\left[c_{j}, d_{j}\right] \subset\left(0,2 \mu_{j}\right)$ and $\lim _{n \rightarrow \infty} r_{j, n}=r_{j}$, for each $j=1, \cdots, M$;

- $\Omega:=\cap_{j=1}^{M} \operatorname{GMEP}\left(\Theta_{j}, \varphi_{j}, B_{j}\right) \cap \cap_{i=1}^{N} \operatorname{VI}\left(C, A_{i}\right) \cap \Xi \neq \emptyset$ and $\mathrm{P}_{\Omega}$ is the metric projection of $H$ onto $\Omega$;

- $\left\{\alpha_{\mathrm{n}}\right\} \subset[0,1],\left\{s_{\mathrm{n}}\right\} \subset\left(0, \min \left\{\frac{1}{2},\|A\|^{-1}\right\}\right)$ and $\left\{s_{\mathrm{t}}\right\}_{\mathrm{t} \in\left(0, \min \left\{1, \frac{2-\bar{\gamma}}{\tau-\gamma}\right\}\right)} \subset\left(0, \min \left\{\frac{1}{2},\|A\|^{-1}\right\}\right)$.

Next, put

$$
\begin{aligned}
\Lambda_{t}^{i} & =P_{C}\left(I-\lambda_{i, t} A_{i}\right) P_{C}\left(I-\lambda_{i-1, t} A_{i-1}\right) \cdots P_{C}\left(I-\lambda_{1, t} A_{1}\right), \quad \forall t \in(0,1), \\
\Lambda_{n}^{i} & =P_{C}\left(I-\lambda_{i, n} A_{i}\right) P_{C}\left(I-\lambda_{i-1, n} A_{i-1}\right) \cdots P_{C}\left(I-\lambda_{1, n} A_{1}\right), \quad \forall n \geqslant 0, \\
\Delta_{t}^{j} & =T_{r_{j, t}, \Theta_{j}}^{\left(\Theta_{j}\right)}\left(I-r_{j, t} B_{j}\right) T_{r_{j-1, t}}^{\left(\Theta_{j-1} \varphi_{j-1}\right)}\left(I-r_{j-1, t} B_{j-1}\right) \cdots T_{r_{1, t}}^{\left(\Theta_{1}, \varphi_{1}\right)}\left(I-r_{1, t} B_{1}\right), \quad \forall t \in(0,1), \\
\Delta_{n}^{j} & =T_{r_{j, n}}^{\left(\Theta_{j}, \varphi_{j}\right)}\left(I-r_{j, n} B_{j}\right) T_{r_{j-1, n}}^{\left(\Theta_{j-1}, \varphi_{j-1}\right)}\left(I-r_{j-1, n} B_{j-1}\right) \cdots T_{r_{1, n}}^{\left(\Theta_{1,}, \varphi_{1}\right)}\left(I-r_{1, n} B_{1}\right), \quad \forall n \geqslant 0,
\end{aligned}
$$

for $i=1, \cdots, N, j=1, \cdots, M, \Lambda_{t}^{0}=\Lambda_{n}^{0}=I$ and $\Delta_{\mathrm{t}}^{0}=\Delta_{n}^{0}=I$, where I is the identity mapping on $\mathrm{H}$.

It is clear that $\operatorname{Fix}\left(\mathrm{T}_{\mathrm{t}}\right)=\operatorname{Fix}\left(\mathrm{T}_{\mathrm{n}}\right)=\Xi$. It is also easy to see that $\Lambda_{\mathrm{t}}^{\mathrm{i}}: \mathrm{C} \rightarrow \mathrm{C}, \Lambda_{\mathrm{n}}^{\mathrm{i}}: \mathrm{C} \rightarrow \mathrm{C}, \Delta_{\mathrm{t}}^{\mathrm{j}}: \mathrm{C} \rightarrow \mathrm{C}$ and $\Delta_{\mathrm{n}}^{\mathrm{j}}: \mathrm{C} \rightarrow \mathrm{C}$ are all nonexpansive.

In this section, we introduce the first multistep relaxed implicit extragradient-like scheme that generates a net $\left\{x_{t}\right\}_{t \in\left(0, \min \left\{1, \frac{2-\bar{\gamma}}{\tau-\gamma l}\right\}\right)}$ in an implicit manner:

$$
\left\{\begin{array}{l}
u_{t}=T_{r_{M, t}}^{\left(\Theta_{M}, \varphi_{M}\right)}\left(I-r_{M, t} B_{M}\right) T_{r_{M-1, t}}^{\left(\Theta_{M-1}, \varphi_{M-1}\right)}\left(I-r_{M-1, t} B_{M-1}\right) \cdots, \\
T_{r_{1, t}}^{\left(\Theta_{1}, \varphi_{1}\right)}\left(I-r_{1, t} B_{1}\right) x_{t}, \\
v_{t}=P_{C}\left(I-\lambda_{N, t} A_{N}\right) P_{C}\left(I-\lambda_{N-1, t} A_{N-1}\right) \cdots P_{C}\left(I-\lambda_{1, t} A_{1}\right) u_{t}, \\
x_{t}=P_{C}\left[\left(I-s_{t} A\right) T_{t} v_{t}+s_{t}\left(t \gamma V x_{t}+(I-t \mu F) T_{t} v_{t}\right)\right] .
\end{array}\right.
$$

We prove the strong convergence of $\left\{x_{t}\right\}$ as $t \rightarrow 0$ to a point $\tilde{x} \in \Omega$ which is a unique solution to the VIP

$$
\langle(A-I) \tilde{x}, p-\tilde{x}\rangle \geqslant 0, \quad \forall p \in \Omega .
$$

For arbitrarily given $x_{0} \in C$, we also propose the second multistep relaxed explicit extragradient-like scheme, which generates a sequence $\left\{x_{n}\right\}$ in an explicit way:

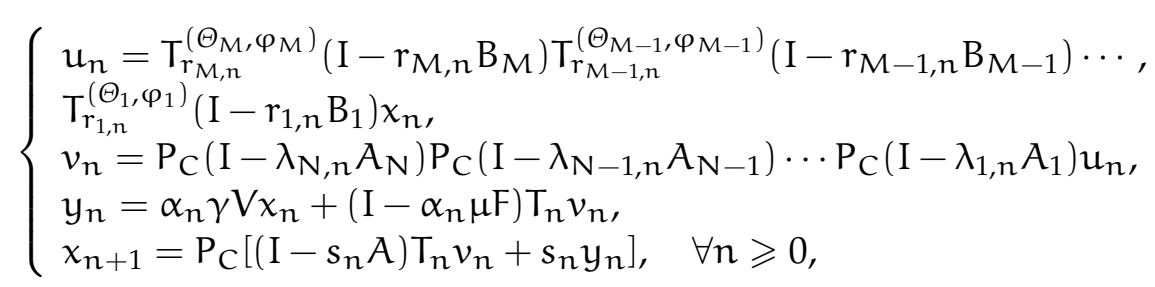

and establish the strong convergence of $\left\{x_{n}\right\}$ as $n \rightarrow \infty$ to the same point $\tilde{x} \in \Omega$, which is also the unique solution to VIP (3.2).

Now, for $t \in\left(0, \min \left\{1, \frac{2-\bar{\gamma}}{\tau-\gamma l}\right\}\right)$, and $s_{t} \in\left(0, \min \left\{\frac{1}{2},\|A\|^{-1}\right\}\right)$, consider a mapping $Q_{t}: C \rightarrow C$ defined by

$$
\mathrm{Q}_{\mathrm{t}} \mathrm{x}=\mathrm{P}_{\mathrm{C}}\left[\left(\mathrm{I}-\mathrm{s}_{\mathrm{t}} \mathrm{A}\right) \mathrm{T}_{\mathrm{t}} \Lambda_{\mathrm{t}}^{\mathrm{N}} \Delta_{\mathrm{t}}^{\mathrm{M}} \mathrm{x}+\mathrm{s}_{\mathrm{t}}\left(\mathrm{t} \gamma \mathrm{V} x+(\mathrm{I}-\mathrm{t} \mu \mathrm{F}) \mathrm{T}_{\mathrm{t}} \Lambda_{\mathrm{t}}^{\mathrm{N}} \Delta_{\mathrm{t}}^{\mathrm{M}} \mathrm{x}\right)\right], \forall x \in \mathrm{C} .
$$

It is easy to see that $Q_{t}$ is a contractive mapping with constant $1-s_{t}(\bar{\gamma}-1+t(\tau-\gamma l))$. By the Banach contraction principle, $Q_{t}$ has a unique fixed point, denoted by $x_{t}$, which uniquely solves the fixed point equation (3.1).

We summary the basic properties of $\left\{x_{t}\right\}$. The argument techniques in [10] can be extended to develop the new argument ones for these basic properties whose proofs will be omitted.

Proposition 3.1. Let $\left\{x_{t}\right\}$ be defined via (3.1). Then 
(i) $\left\{x_{\mathrm{t}}\right\}$ is bounded for $\mathrm{t} \in\left(0, \min \left\{1, \frac{2-\bar{\gamma}}{\tau-\gamma l}\right\}\right)$;

(ii) $\lim _{\mathrm{t} \rightarrow 0}\left\|\mathrm{x}_{\mathrm{t}}-\mathrm{T}_{\mathrm{t}} \mathrm{x}_{\mathrm{t}}\right\|=0, \lim _{\mathrm{t} \rightarrow 0}\left\|\mathrm{x}_{\mathrm{t}}-\Lambda_{\mathrm{t}}^{\mathrm{N}} \mathrm{x}_{\mathrm{t}}\right\|=0$ and $\lim _{\mathrm{t} \rightarrow 0}\left\|\mathrm{x}_{\mathrm{t}}-\Delta_{\mathrm{t}}^{\mathrm{M}} \mathrm{x}_{\mathrm{t}}\right\|=0$ provided $\lim _{\mathrm{t} \rightarrow 0} \lambda_{\mathrm{t}}=$ $\frac{2}{\mathrm{~L}}\left(\Leftrightarrow \lim _{\mathrm{t} \rightarrow 0} s_{\mathrm{t}}=0\right) ;$

(iii) $x_{\mathrm{t}}:\left(0, \min \left\{1, \frac{2-\bar{\gamma}}{\tau-\gamma \mathrm{l}}\right\}\right) \rightarrow \mathrm{H}$ is locally Lipschitzian provided $\mathrm{s}_{\mathrm{t}}:\left(0, \min \left\{1, \frac{2-\bar{\gamma}}{\tau-\gamma \mathrm{l}}\right\}\right) \rightarrow\left(0, \min \left\{\frac{1}{2},\|\mathrm{~A}\|^{-1}\right\}\right)$ is locally Lipschitzian, $\lambda_{i, t}:\left(0, \min \left\{1, \frac{2-\bar{\gamma}}{\tau-\gamma l}\right\}\right) \rightarrow\left[a_{i}, b_{i}\right]$ is locally Lipschitzian for each $i=1, \cdots, N$ and $r_{j, t}:\left(0, \min \left\{1, \frac{2-\bar{\gamma}}{\tau-\gamma l}\right\}\right) \rightarrow\left[c_{j}, d_{j}\right]$ is locally Lipschitzian for each $j=1, \cdots, M$;

(iv) $x_{\mathrm{t}}$ defines a continuous path from $\left(0, \min \left\{1, \frac{2-\bar{\gamma}}{\tau-\gamma l}\right\}\right)$ into $\mathrm{H}$ provided

$$
s_{\mathrm{t}}:\left(0, \min \left\{1, \frac{2-\bar{\gamma}}{\tau-\gamma l}\right\}\right) \rightarrow\left(0, \min \left\{\frac{1}{2},\|\mathrm{~A}\|^{-1}\right)\right.
$$

is continuous, $\lambda_{i, t}:\left(0, \min \left\{1, \frac{2-\bar{\gamma}}{\tau-\gamma l}\right\}\right) \rightarrow\left[a_{i}, b_{i}\right]$ is continuous for each $i=1, \cdots, N$, and $r_{j, t}:\left(0, \min \left\{1, \frac{2-\bar{\gamma}}{\tau-\gamma l}\right\}\right) \rightarrow\left[c_{j}, d_{j}\right]$ is continuous for each $j=1, \cdots, M$.

We prove the following theorem for strong convergence of the net $\left\{x_{t}\right\}$ as $t \rightarrow 0$, which guarantees the existence of solutions of the variational inequality (3.2).

Theorem 3.2. Let the net $\left\{x_{t}\right\}$ be defined via (3.1). If $\lim _{t \rightarrow 0} s_{t}=0$, then $x_{t}$ converges strongly to a point $\tilde{x} \in \Omega$ as $\mathrm{t} \rightarrow 0$, which solves the VIP (3.2). Equivalently, we have $\mathrm{P}_{\Omega}(2 \mathrm{I}-\mathrm{A}) \tilde{\mathrm{x}}=\tilde{\mathrm{x}}$.

Proof. We first note that we have the uniqueness of solutions of the VIP (3.2) which is indeed a consequence of the strong monotonicity of $A-I$.

Next, we prove that $x_{t} \rightarrow \tilde{x}$ as $t \rightarrow 0$. Observing $\operatorname{Fix}\left(T_{t}\right)=\Xi$, from (3.1) we write for given $p \in \Omega$,

$$
\begin{aligned}
x_{t}-p & =x_{t}-w_{t}+w_{t}-p \\
= & x_{t}-w_{t}+\left(I-s_{t} A\right) T_{t} v_{t}+s_{t}\left(t \gamma V x_{t}+(I-t \mu F) T_{t} v_{t}\right)-p \\
= & x_{t}-w_{t}+\left(I-s_{t} A\right)\left(T_{t} v_{t}-T_{t} p\right)+s_{t}\left[t \gamma V x_{t}+(I-t \mu F) T_{t} v_{t}-p\right]+s_{t}(I-A) p \\
= & x_{t}-w_{t}+\left(I-s_{t} A\right)\left(T_{t} v_{t}-T_{t} p\right)+s_{t}\left[t\left(\gamma V x_{t}-\mu F p\right)+(I-t \mu F) T_{t} v_{t}-(I-t \mu F) p\right] \\
& +s_{t}(I-A) p,
\end{aligned}
$$

where $w_{t}=\left(I-s_{t} A\right) T_{t} v_{t}+s_{t}\left(t \gamma V x_{t}+(I-t \mu F) T_{t} v_{t}\right)$. Then, by Proposition 2.1 (i), we have

$$
\begin{aligned}
\left\|x_{t}-p\right\|^{2}= & \left\langle x_{t}-w_{t}, x_{t}-p\right\rangle+\left\langle\left(I-s_{t} A\right)\left(T_{t} v_{t}-T_{t} p\right), x_{t}-p\right\rangle+s_{t}\left[t\left\langle\gamma V x_{t}-\mu F p, x_{t}-p\right\rangle\right. \\
& \left.+\left\langle(I-t \mu F) T_{t} v_{t}-(I-t \mu F) p, x_{t}-p\right\rangle\right]+s_{t}\left\langle(I-A) p, x_{t}-p\right\rangle \\
\leqslant & \left(1-s_{t} \bar{\gamma}\right)\left\|x_{t}-p\right\|^{2}+s_{t}\left[(1-t \tau)\left\|x_{t}-p\right\|^{2}+t \gamma l\left\|x_{t}-p\right\|^{2}\right. \\
& \left.+t\left\langle(\gamma V-\mu F) p, x_{t}-p\right\rangle\right]+s_{t}\left\langle(I-A) p, x_{t}-p\right\rangle \\
= & {\left[1-s_{t}(\bar{\gamma}-1+t(\tau-\gamma l)]\left\|x_{t}-p\right\|^{2}+s_{t}\left(t\left\langle(\gamma V-\mu F) p, x_{t}-p\right\rangle+\left\langle(I-A) p, x_{t}-p\right\rangle\right) .\right.}
\end{aligned}
$$

Therefore,

$$
\left\|x_{t}-p\right\|^{2} \leqslant \frac{1}{\bar{\gamma}-1+t(\tau-\gamma l)}\left(t\left\langle(\gamma V-\mu F) p, x_{t}-p\right\rangle+\left\langle(I-A) p, x_{t}-p\right\rangle\right) .
$$

Since the net $\left\{x_{t}\right\}_{t \in\left(0, \min \left\{1, \frac{2-\gamma}{\tau-\gamma l}\right\}\right)}$ is bounded (due to Proposition $\left.3.1(i)\right)$, we know that if $\left\{t_{n}\right\}$ is a subsequence in $\left(0, \min \left\{1, \frac{2-\bar{\gamma}}{\tau-\gamma l}\right\}\right)$ such that $t_{n} \rightarrow 0$ and $x_{t_{n}} \rightarrow x^{*}$, then from (3.4), we obtain $x_{t_{n}} \rightarrow x^{*}$. Let us show that $x^{*} \in \Omega$. Indeed, by Proposition 3.1 (ii), we know that $\lim _{n \rightarrow \infty}\left\|x_{t_{n}}-T_{t_{n}} x_{t_{n}}\right\|=0$. Observe that

$$
\begin{aligned}
\left\|P_{C}\left(I-\lambda_{t_{n}} \nabla f\right) x_{t_{n}}-x_{t_{n}}\right\| & =\left\|s_{t_{n}} x_{t_{n}}+\left(1-s_{t_{n}}\right) T_{t_{n}} x_{t_{n}}-x_{t_{n}}\right\| \\
& =\left(1-s_{t_{n}}\right)\left\|T_{t_{n}} x_{t_{n}}-x_{t_{n}}\right\| \\
& \leqslant\left\|T_{t_{n}} x_{t_{n}}-x_{t_{n}}\right\|,
\end{aligned}
$$


where $s_{t_{n}}=\frac{2-\lambda_{t_{n}} L}{4} \in\left(0, \frac{1}{2}\right)$, for $\lambda_{t_{n}} \in\left(0, \frac{2}{L}\right)$. Hence we have

$$
\begin{aligned}
\left\|P_{C}\left(I-\frac{2}{L} \nabla f\right) x_{t_{n}}-x_{t_{n}}\right\| & \leqslant\left\|P_{C}\left(I-\frac{2}{L} \nabla f\right) x_{t_{n}}-P_{C}\left(I-\lambda_{t_{n}} \nabla f\right) x_{t_{n}}\right\|+\left\|P_{C}\left(I-\lambda_{t_{n}} \nabla f\right) x_{t_{n}}-x_{t_{n}}\right\| \\
& \leqslant\left\|\left(I-\frac{2}{L} \nabla f\right) x_{t_{n}}-\left(I-\lambda_{t_{n}} \nabla f\right) x_{t_{n}}\right\|+\left\|P_{C}\left(I-\lambda_{t_{n}} \nabla f\right) x_{t_{n}}-x_{t_{n}}\right\| \\
& \leqslant\left(\frac{2}{L}-\lambda_{t_{n}}\right)\left\|\nabla f\left(x_{t_{n}}\right)\right\|+\left\|T_{t_{n}} x_{t_{n}}-x_{t_{n}}\right\| .
\end{aligned}
$$

From the boundedness of $\left\{x_{t_{n}}\right\}, s_{t_{n}} \rightarrow 0\left(\Leftrightarrow \lambda_{t_{n}} \rightarrow \frac{2}{L}\right)$ and $\left\|T_{t_{n}} x_{t_{n}}-x_{t_{n}}\right\| \rightarrow 0$, it follows that

$$
\left\|x^{*}-P_{C}\left(I-\frac{2}{L} \nabla f\right) x^{*}\right\|=\lim _{n \rightarrow \infty}\left\|x_{t_{n}}-P_{C}\left(I-\frac{2}{L} \nabla f\right) x_{t_{n}}\right\|=0 .
$$

So, $x^{*} \in \operatorname{VI}(C, \nabla f)=\Xi$.

Furthermore, it can be shown that $\Delta_{t_{n}}^{j} x_{t_{n}} \rightarrow x^{*}, \Lambda_{t_{n}}^{m} u_{t_{n}} \rightarrow x^{*}, u_{t_{n}} \rightarrow x^{*}$ and $v_{t_{n}} \rightarrow x^{*}$ where $j \in\{1, \cdots, M\}, m \in\{1, \cdots, N\}$. Let

$$
\widetilde{\mathrm{T}}_{\mathrm{m}} v= \begin{cases}\mathrm{A}_{\mathrm{m}} v+\mathrm{N}_{\mathrm{C}} v, & v \in \mathrm{C}, \\ \emptyset, & v \notin \mathrm{C},\end{cases}
$$

where $m \in\{1, \cdots, N\}$. By a standard argument, we can show that

$$
\left\langle v-x^{*}, u\right\rangle \geqslant 0 \text {. }
$$

Since $\widetilde{T}_{m}$ is maximal monotone, we have $x^{*} \in \widetilde{T}_{m}^{-1} 0$ and hence $x^{*} \in \operatorname{VI}\left(C, A_{m}\right), m=1,2, \cdots, N$, which implies $x^{*} \in \cap_{m=1}^{N} \operatorname{VI}\left(C, A_{m}\right)$. Next we prove that $x^{*} \in \cap_{j=1}^{M} \operatorname{GMEP}\left(\Theta_{j}, \varphi_{j}, B_{j}\right)$. Since $\Delta_{t_{n}}^{j} x_{t_{n}}=T_{r_{j, t n}}^{\left(\Theta_{j}, \varphi_{j}\right)}(I-$ $\left.r_{j, t_{n}} B_{j}\right) \Delta_{t_{n}}^{j-1} x_{t_{n}}, j \in\{1, \cdots, M\}$, we have

$$
\Theta_{j}\left(\Delta_{t_{n}}^{j} x_{t_{n}}, y\right)+\varphi_{j}(y)-\varphi_{j}\left(\Delta_{t_{n}}^{j} x_{t_{n}}\right)+\left\langle B_{j} \Delta_{t_{n}}^{j-1} x_{t_{n}}, y-\Delta_{t_{n}}^{j} x_{t_{n}}\right\rangle+\left\langle y-\Delta_{t_{n}}^{j} x_{t_{n}}, \frac{\Delta_{t_{n}}^{j} x_{t_{n}}-\Delta_{t_{n}}^{j-1} x_{t_{n}}}{r_{j, t_{n}}}\right\rangle \geqslant 0 .
$$

By (A2), we have

$$
\varphi_{j}(y)-\varphi_{j}\left(\Delta_{t_{n}}^{j} x_{t_{n}}\right)+\left\langle B_{j} \Delta_{t_{n}}^{j-1} x_{t_{n}} y-\Delta_{t_{n}}^{j} x_{t_{n}}\right\rangle+\left\langle y-\Delta_{t_{n}}^{j} x_{t_{n}} \frac{\Delta_{t_{n}}^{j} x_{t_{n}}-\Delta_{t_{n}}^{j-1} x_{t_{n}}}{r_{j, t_{n}}}\right\rangle \geqslant \Theta_{j}\left(y, \Delta_{t_{n}}^{j} x_{t_{n}}\right) .
$$

Let $z_{\mathrm{t}}=\mathrm{t} \mathrm{y}+(1-\mathrm{t}) \mathrm{x}^{*}$ for all $\mathrm{t} \in(0,1]$ and $\mathrm{y} \in \mathrm{C}$. This implies that $z_{\mathrm{t}} \in \mathrm{C}$. Then, we have

$$
\begin{aligned}
& \left\langle z_{t}-\Delta_{t_{n}}^{j} x_{t_{n}}, B_{j} z_{t}\right\rangle \geqslant \varphi_{j}\left(\Delta_{t_{n}}^{j} x_{t_{n}}\right)-\varphi_{j}\left(z_{t}\right)+\left\langle z_{t}-\Delta_{t_{n}}^{j} x_{t_{n}}, B_{j} z_{t}\right\rangle-\left\langle z_{t}-\Delta_{t_{n}}^{j} x_{t_{n}}, B_{j} \Delta_{t_{n}}^{j-1} x_{t_{n}}\right\rangle \\
& -\left\langle z_{t}-\Delta_{\mathfrak{t}_{n}}^{j} x_{t_{n}}, \frac{\Delta_{t_{n}}^{j} x_{t_{n}}-\Delta_{t_{n}}^{j-1} x_{t_{n}}}{r_{j, t_{n}}}\right\rangle+\Theta_{j}\left(z_{t}, \Delta_{t_{n}}^{j} x_{t_{n}}\right) \\
& =\varphi_{j}\left(\Delta_{t_{n}}^{j} x_{t_{n}}\right)-\varphi_{j}\left(z_{t}\right)+\left\langle z_{t}-\Delta_{t_{n}}^{j} x_{t_{n}}, B_{j} z_{t}-B_{j} \Delta_{t_{n}}^{j} x_{t_{n}}\right\rangle \\
& +\left\langle z_{t}-\Delta_{t_{n}}^{j} x_{t_{n}}, B_{j} \Delta_{t_{n}}^{j} x_{t_{n}}-B_{j} \Delta_{t_{n}}^{j-1} x_{t_{n}}\right\rangle-\left\langle z_{t}-\Delta_{t_{n}}^{j} x_{t_{n}}, \frac{\Delta_{t_{n}}^{j} x_{t_{n}}-\Delta_{t_{n}}^{j-1} x_{t_{n}}}{r_{j, t_{n}}}\right\rangle \\
& +\Theta_{j}\left(z_{t}, \Delta_{t_{n}}^{j} x_{t_{n}}\right) \text {. }
\end{aligned}
$$

Note that $\left\|B_{j} \Delta_{t_{n}}^{j} x_{t_{n}}-B_{j} \Delta_{t_{n}}^{j-1} x_{t_{n}}\right\| \rightarrow 0$ as $n \rightarrow \infty$. Furthermore, by the monotonicity of $B_{j}$, we obtain $\left\langle z_{t}-\Delta_{t_{n}}^{j} x_{t_{n}}, B_{j} z_{t}-B_{j} \Delta_{t_{n}}^{j} x_{t_{n}}\right\rangle \geqslant 0$. Then, by (A4) we obtain

$$
\left\langle z_{\mathfrak{t}}-x^{*}, B_{j} z_{\mathfrak{t}}\right\rangle \geqslant \varphi_{j}\left(x^{*}\right)-\varphi_{j}\left(z_{\mathfrak{t}}\right)+\Theta_{j}\left(z_{t}, x^{*}\right) .
$$


Utilizing (A1), (A4) and (3.5), we obtain

$$
\begin{aligned}
0 & =\Theta_{j}\left(z_{t}, z_{t}\right)+\varphi_{j}\left(z_{t}\right)-\varphi_{j}\left(z_{t}\right) \\
& \leqslant t \Theta_{j}\left(z_{t}, y\right)+(1-t) \Theta_{j}\left(z_{t}, x^{*}\right)+t \varphi_{j}(y)+(1-t) \varphi_{j}\left(x^{*}\right)-\varphi_{j}\left(z_{t}\right) \\
& \leqslant t\left[\Theta_{j}\left(z_{t}, y\right)+\varphi_{j}(y)-\varphi_{j}\left(z_{t}\right)\right]+(1-t)\left\langle z_{t}-x^{*}, B_{j} z_{t}\right\rangle \\
& =t\left[\Theta_{j}\left(z_{t}, y\right)+\varphi_{j}(y)-\varphi_{j}\left(z_{t}\right)\right]+(1-t) t\left\langle y-x^{*}, B_{j} z_{t}\right\rangle,
\end{aligned}
$$

and hence

$$
0 \leqslant \Theta_{j}\left(z_{t}, y\right)+\varphi_{j}(y)-\varphi_{j}\left(z_{t}\right)+(1-t)\left\langle y-x^{*}, B_{j} z_{t}\right\rangle .
$$

Letting $t \rightarrow 0$, we have for each $y \in C$,

$$
0 \leqslant \Theta_{j}\left(x^{*}, y\right)+\varphi_{j}(y)-\varphi_{j}\left(x^{*}\right)+\left\langle y-x^{*}, B_{j} x^{*}\right\rangle .
$$

This implies that $x^{*} \in \operatorname{GMEP}\left(\Theta_{j}, \varphi_{j}, B_{j}\right)$ and hence $x^{*} \in \cap_{j=1}^{M} \operatorname{GMEP}\left(\Theta_{j}, \varphi_{j}, B_{j}\right)$. Therefore,

$$
x^{*} \in \cap_{j=1}^{M} \operatorname{GMEP}\left(\Theta_{j}, \varphi_{j}, B_{j}\right) \cap \cap_{i=1}^{N} \operatorname{VI}\left(C, A_{i}\right) \cap \Xi=: \Omega .
$$

Next, we prove that $x_{t} \rightarrow \tilde{x}$ as $t \rightarrow 0$. First, let us assert that $x^{*}$ is a solution of the VIP (3.2). As a matter of fact, since

$$
x_{t}=x_{t}-w_{t}+\left(I-s_{t} A\right) T_{t} \Lambda_{t}^{N} \Delta_{t}^{M} x_{t}+s_{t}\left(t \gamma V x_{t}+(I-t \mu F) T_{t} \Lambda_{t}^{N} \Delta_{t}^{M} x_{t}\right)
$$

we have

$$
x_{\mathrm{t}}-\mathrm{T}_{\mathrm{t}} \Lambda_{\mathrm{t}}^{\mathrm{N}} \Delta_{\mathrm{t}}^{\mathrm{M}} \mathrm{x}_{\mathrm{t}}=\mathrm{x}_{\mathrm{t}}-w_{\mathrm{t}}+s_{\mathrm{t}}(\mathrm{I}-\mathrm{A}) \mathrm{T}_{\mathrm{t}} \Lambda_{\mathrm{t}}^{\mathrm{N}} \Delta_{\mathrm{t}}^{\mathrm{M}} \mathrm{x}_{\mathrm{t}}+s_{\mathrm{t}} \mathrm{t}\left(\gamma V \mathrm{x}_{\mathrm{t}}-\mu \mathrm{FT} \mathrm{T}_{\mathrm{t}} \Lambda_{\mathrm{t}}^{\mathrm{N}} \Delta_{\mathrm{t}}^{\mathrm{M}} \mathrm{x}_{\mathrm{t}}\right)
$$

Since $\mathrm{T}_{\mathrm{t}}, \Lambda_{\mathrm{t}}^{\mathrm{N}}$ and $\Delta_{\mathrm{t}}^{\mathrm{M}}$ are nonexpansive mappings, $\mathrm{I}-\mathrm{T}_{\mathrm{t}} \Lambda_{\mathrm{t}}^{\mathrm{N}} \Delta_{\mathrm{t}}^{\mathrm{M}}$ is monotone. So from the monotonicity of $\mathrm{I}-\mathrm{T}_{\mathrm{t}} \Lambda_{\mathrm{t}}^{\mathrm{N}} \Delta_{\mathrm{t}}^{\mathrm{M}}$, it follows that, for $\mathrm{p} \in \Omega$,

$$
\begin{aligned}
0 \leqslant & \left\langle\left(\mathrm{I}-\mathrm{T}_{\mathrm{t}} \Lambda_{\mathrm{t}}^{\mathrm{N}} \Delta_{\mathrm{t}}^{\mathrm{M}}\right) x_{\mathrm{t}}-\left(\mathrm{I}-\mathrm{T}_{\mathrm{t}} \Lambda_{\mathrm{t}}^{\mathrm{N}} \Delta_{\mathrm{t}}^{\mathrm{M}}\right) p, x_{\mathrm{t}}-\mathrm{p}\right\rangle=\left\langle\left(\mathrm{I}-\mathrm{T}_{\mathrm{t}} \Lambda_{\mathrm{t}}^{\mathrm{N}} \Delta_{\mathrm{t}}^{\mathrm{M}}\right) x_{\mathrm{t}}, x_{\mathrm{t}}-\mathrm{p}\right\rangle \\
= & \left\langle x_{\mathrm{t}}-w_{\mathrm{t}}, x_{\mathrm{t}}-\mathrm{p}\right\rangle+s_{\mathrm{t}}\left\langle(\mathrm{I}-\mathrm{A}) \mathrm{T}_{\mathrm{t}} \Lambda_{\mathrm{t}}^{\mathrm{N}} \Delta_{\mathrm{t}}^{\mathrm{M}} x_{\mathrm{t}}, x_{\mathrm{t}}-\mathrm{p}\right\rangle+s_{\mathrm{t}} \mathrm{t}\left\langle\gamma \mathrm{V} x_{\mathrm{t}}-\mu \mathrm{FT} \mathrm{T}_{\mathrm{t}} \Lambda_{\mathrm{t}}^{\mathrm{N}} \Delta_{\mathrm{t}}^{\mathrm{M}} x_{\mathrm{t}}, x_{\mathrm{t}}-\mathrm{p}\right\rangle \\
\leqslant & s_{\mathrm{t}}\left\langle(\mathrm{I}-\mathrm{A}) \mathrm{T}_{\mathrm{t}} \Lambda_{\mathrm{t}}^{\mathrm{N}} \Delta_{\mathrm{t}}^{\mathrm{M}} x_{\mathrm{t}}, x_{\mathrm{t}}-\mathrm{p}\right\rangle+s_{\mathrm{t}} \mathrm{t}\left\langle\gamma \mathrm{V} x_{\mathrm{t}}-\mu \mathrm{FT} \mathrm{T}_{\mathrm{t}} \Lambda_{\mathrm{t}}^{\mathrm{N}} \Delta_{\mathrm{t}}^{\mathrm{M}} x_{\mathrm{t}}, x_{\mathrm{t}}-\mathrm{p}\right\rangle \\
= & s_{\mathrm{t}}\left\langle(\mathrm{I}-\mathrm{A}) x_{\mathrm{t}}, x_{\mathrm{t}}-\mathrm{p}\right\rangle+s_{\mathrm{t}}\left\langle(\mathrm{I}-\mathrm{A})\left(\mathrm{T}_{\mathrm{t}} \Lambda_{\mathrm{t}}^{\mathrm{N}} \Delta_{\mathrm{t}}^{\mathrm{M}}-\mathrm{I}\right) \mathrm{x}_{\mathrm{t}}, x_{\mathrm{t}}-\mathrm{p}\right\rangle \\
& +s_{\mathrm{t}} \mathrm{t}\left\langle\gamma \mathrm{V} x_{\mathrm{t}}-\mu \mathrm{FT}_{\mathrm{t}} \Lambda_{\mathrm{t}}^{\mathrm{N}} \Delta_{\mathrm{t}}^{\mathrm{M}} x_{\mathrm{t}}, x_{\mathrm{t}}-\mathrm{p}\right\rangle .
\end{aligned}
$$

This implies that

$$
\left\langle(A-I) x_{t}, x_{t}-p\right\rangle \leqslant\left\langle(I-A)\left(T_{t} \Lambda_{t}^{N} \Delta_{t}^{M}-I\right) x_{t}, x_{t}-p\right\rangle+t\left\langle\gamma V x_{t}-\mu F T_{t} \Lambda_{t}^{N} \Delta_{t}^{M} x_{t}, x_{t}-p\right\rangle .
$$

That is,

$$
\left\langle(A-I) x_{t}, x_{t}-p\right\rangle \leqslant\left\langle(I-A)\left(T_{t} v_{t}-x_{t}\right), x_{t}-p\right\rangle+t\left\langle\gamma V x_{t}-\mu F T_{t} v_{t}, x_{t}-p\right\rangle .
$$

Now, replacing $t$ in (3.6) with $t_{n}$ and letting $n \rightarrow \infty$, noticing the boundedness of $\left\{\gamma V x_{t_{n}}-\mu \mathrm{FT}_{t_{n}} v_{t_{n}}\right\}$ and the fact that $(I-A)\left(T_{t_{n}} v_{t_{n}}-x_{t_{n}}\right) \rightarrow 0$ as $n \rightarrow \infty$, we obtain

$$
\left\langle(A-I) x^{*}, x^{*}-p\right\rangle \leqslant 0 .
$$

That is, $x^{*} \in \Omega$ is a solution of the VIP (3.2), hence $x^{*}=\tilde{x}$ by uniqueness. In summary, we have proven that each cluster point of $\left\{x_{t}\right\}$ (as $t \rightarrow 0$ ) equals $\tilde{x}$. Consequently, $x_{t} \rightarrow \tilde{x}$ as $t \rightarrow 0$.

Now, we prove the following result in order to establish the strong convergence of the sequence $\left\{x_{n}\right\}$ generated by the multistep relaxed explicit extragradient-like scheme (3.3). 
Theorem 3.3. Let $\left\{x_{n}\right\}$ be the sequence generated by the explicit scheme (3.3), where $\left\{\alpha_{n}\right\}$ and $\left\{s_{n}\right\}$ satisfy the following condition:

(C1) $\left\{\alpha_{n}\right\} \subset[0,1],\left\{s_{n}\right\} \subset\left(0, \frac{1}{2}\right)$ and $\alpha_{n} \rightarrow 0, s_{n} \rightarrow 0$ as $n \rightarrow \infty$.

Let LIM be a Banach limit. Then

$$
\operatorname{LIM}_{n}\left\langle(A-I) \tilde{x}, \tilde{x}-x_{n}\right\rangle \leqslant 0,
$$

where $\tilde{x}=\lim _{\mathrm{t} \rightarrow 0^{+}} x_{\mathrm{t}}$ with $\mathrm{x}_{\mathrm{t}}$ being defined by

$$
x_{t}=P_{C}\left[\left(I-s_{t} A\right) T \Lambda^{N} \Delta^{M} x_{t}+s_{t}\left(t \gamma V x_{t}+(I-t \mu F) T \Lambda^{N} \Delta^{M} x_{t}\right)\right],
$$

where $\mathrm{T}, \Lambda^{\mathrm{N}}, \Delta^{\mathrm{M}}: \mathrm{C} \rightarrow \mathrm{C}$ are defined by

$$
\begin{aligned}
\mathrm{T} x & =\mathrm{P}_{\mathrm{C}}\left(\mathrm{I}-\frac{2}{\mathrm{~L}} \nabla f\right) x, \\
\Lambda^{\mathrm{N}} \mathrm{x} & =\mathrm{P}_{\mathrm{C}}\left(\mathrm{I}-\lambda_{\mathrm{N}} A_{\mathrm{N}}\right) \cdots \mathrm{P}_{\mathrm{C}}\left(\mathrm{I}-\lambda_{1} A_{1}\right) x
\end{aligned}
$$

and

$$
\Delta^{M} x=T_{r_{M}}^{\left(\Theta_{M}, \varphi_{M}\right)}\left(I-r_{M} B_{M}\right) \cdots T_{r_{1}}^{\left(\Theta_{1}, \varphi_{1}\right)}\left(I-r_{1} B_{1}\right) \chi,
$$

for $\lambda_{i} \in\left[a_{i}, b_{i}\right] \subset\left(0,2 \eta_{i}\right), i=1, \ldots, N$ and $r_{j} \in\left[c_{j}, d_{j}\right] \subset\left(0,2 \mu_{j}\right), j=1, \ldots, M$.

Proof. First, note that from the condition (C1), without loss of generality, we may assume that $0<s_{n} \leqslant$ $\|A\|^{-1}$ for all $n \geqslant 0$. Let $\left\{x_{\mathrm{t}}\right\}$ be the net generated by (3.7). Since $\mathrm{T}, \Lambda^{\mathrm{N}}$ and $\Delta^{\mathrm{M}}$ are nonexpansive self-mappings on $\mathrm{C}$, by Theorem 3.2 with $\mathrm{T}_{\mathrm{t}}=\mathrm{T}, \Lambda_{\mathrm{t}}^{\mathrm{N}}=\Lambda^{\mathrm{N}}$ and $\Delta_{\mathrm{t}}^{\mathrm{M}}=\Delta^{\mathrm{M}}$, there exists $\lim _{\mathrm{t} \rightarrow 0} x_{\mathrm{t}} \in \Omega$. Denote it by $\tilde{x}$. Moreover, $\tilde{x}$ is the unique solution of the VIP (3.2). From Proposition 3.1 (i) with $T_{t}=$ $\mathrm{T}, \Lambda_{\mathrm{t}}^{\mathrm{N}}=\Lambda^{\mathrm{N}}$ and $\Delta_{\mathrm{t}}^{\mathrm{M}}=\Delta^{\mathrm{M}}$, we know that $\left\{\mathrm{x}_{\mathrm{t}}\right\}$ is bounded and so are the nets $\left\{\mathrm{V} x_{\mathrm{t}}\right\},\left\{\Delta^{\mathrm{M}} \mathrm{x}_{\mathrm{t}}\right\},\left\{\Lambda^{\mathrm{N}} \Delta^{\mathrm{M}} x_{\mathrm{t}}\right\}$ and $\left\{\mathrm{FT} \Lambda^{\mathrm{N}} \Delta^{\mathrm{M}} \mathrm{x}_{\mathrm{t}}\right\}$.

First of all, let us show that $\left\{x_{n}\right\}$ is bounded. To this end, take $p \in \Omega$. Then we get

$$
\begin{aligned}
\left\|y_{n}-p\right\| & =\left\|\alpha_{n} \gamma V x_{n}+\left(I-\alpha_{n} \mu F\right) T_{n} \Lambda_{n}^{N} \Delta_{n}^{M} x_{n}-p\right\| \\
& =\left\|\alpha_{n}\left(\gamma V x_{n}-\mu F p\right)+\left(I-\alpha_{n} \mu F\right) T_{n} \Lambda_{n}^{N} \Delta_{n}^{M} x_{n}-\left(I-\alpha_{n} \mu F\right) T_{n} \Lambda_{n}^{N} \Delta_{n}^{M} p\right\| \\
& \leqslant \alpha_{n} \gamma l\left\|x_{n}-p\right\|+\alpha_{n}\|(\gamma V-\mu F) p\|+\left(1-\alpha_{n} \tau\right)\left\|x_{n}-p\right\| \\
& =\left(1-\alpha_{n}(\tau-\gamma l)\right)\left\|x_{n}-p\right\|+\alpha_{n}\|(\gamma V-\mu F) p\|,
\end{aligned}
$$

which together with Lemma 2.15, implies that

$$
\begin{aligned}
& \left\|x_{n+1}-p\right\|=\left\|P_{C}\left[\left(I-s_{n} A\right) T_{n} \Lambda_{n}^{N} \Delta_{n}^{M} x_{n}+s_{n} y_{n}\right]-p\right\| \\
& \leqslant\left\|\left(I-s_{n} A\right) T_{n} \Lambda_{n}^{N} \Delta_{n}^{M} x_{n}+\beta_{n} y_{n}-p\right\| \\
& =\left\|\left(I-s_{n} A\right) T_{n} \Lambda_{n}^{N} \Delta_{n}^{M} x_{n}-\left(I-s_{n} A\right) T_{n} \Lambda_{n}^{N} \Delta_{n}^{M} p+s_{n}\left(y_{n}-p\right)+s_{n}(I-A) p\right\| \\
& \leqslant\left\|\left(I-s_{n} A\right) T_{n} \Lambda_{n}^{N} \Delta_{n}^{M} x_{n}-\left(I-s_{n} A\right) T_{n} \Lambda_{n}^{N} \Delta_{n}^{M} p\right\|+s_{n}\left\|y_{n}-p\right\|+s_{n}\|I-A\|\|p\| \\
& \leqslant\left(1-s_{n} \bar{\gamma}\right)\left\|x_{n}-p\right\|+s_{n}\left[\left(1-\alpha_{n}(\tau-\gamma l)\right)\left\|x_{n}-p\right\|\right. \\
& \left.+\alpha_{n}\|(\gamma V-\mu F) p\|\right]+s_{n}\|I-A\|\|p\| \\
& \leqslant\left(1-s_{n}(\bar{\gamma}-1)\right)\left\|x_{n}-p\right\|+s_{n}(\|(\gamma V-\mu F) p\|+\|I-A\|\|p\|) \\
& =\left(1-s_{\mathfrak{n}}(\bar{\gamma}-1)\right)\left\|x_{\mathfrak{n}}-p\right\|+s_{\mathfrak{n}}(\bar{\gamma}-1) \frac{\|(\gamma \mathrm{V}-\mu \mathrm{F}) \mathrm{p}\|+\|\mathrm{I}-\mathrm{A}\|\|\mathrm{p}\|}{\bar{\gamma}-1} \\
& \leqslant \max \left\{\left\|x_{n}-p\right\|, \frac{\|(\gamma V-\mu F) p\|+\|I-A\|\|p\|_{1}}{\bar{\gamma}-1}\right\} \text {. }
\end{aligned}
$$

By induction

$$
\left\|x_{n}-p\right\| \leqslant \max \left\{\left\|x_{0}-p\right\|, \frac{\|(\gamma V-\mu F) p\|+\|I-A\|\|p\|}{\bar{\gamma}-1}\right\}, \quad \forall n \geqslant 0
$$


This implies that $\left\{x_{n}\right\}$ is bounded and so are $\left\{V x_{n}\right\},\left\{u_{n}\right\},\left\{v_{n}\right\},\left\{\mathrm{FT}_{n} v_{n}\right\}$ and $\left\{y_{n}\right\}$. Thus, utilizing the control condition (C1), we get

$$
\begin{aligned}
\left\|x_{n+1}-T_{n} v_{n}\right\| & =\left\|P_{C}\left[\left(I-s_{n} A\right) T_{n} v_{n}+s_{n} y_{n}\right]-T_{n} v_{n}\right\| \\
& \leqslant\left\|\left(I-s_{n} A\right) T_{n} v_{n}+s_{n} y_{n}-T_{n} v_{n}\right\| \\
& =s_{n}\left\|y_{n}-A T_{n} v_{n}\right\| \rightarrow 0 \text { as } n \rightarrow \infty
\end{aligned}
$$

One can show that

$$
\left\|\mathrm{T} \Lambda^{\mathrm{N}} \Delta^{\mathrm{M}} \mathrm{x}_{\mathrm{n}}-\mathrm{T}_{\mathrm{n}} \Lambda_{\mathrm{n}}^{\mathrm{N}} \Delta_{\mathrm{n}}^{\mathrm{M}} \mathrm{x}_{\mathrm{n}}\right\| \leqslant\left\|\Lambda^{\mathrm{N}} \Delta^{\mathrm{M}} \mathrm{x}_{\mathrm{n}}-\Lambda_{\mathrm{n}}^{\mathrm{N}} \Delta_{\mathrm{n}}^{\mathrm{M}} \mathrm{x}_{\mathrm{n}}\right\|+\widehat{\mathrm{M}}\left|\frac{2}{\mathrm{~L}}-\lambda_{\mathrm{n}}\right|,
$$

where $\sup _{n \geqslant 0}\left\{L\left\|P_{C}\left(I-\frac{2}{L} \nabla f\right) v_{n}\right\|+4\left\|\nabla f\left(v_{n}\right)\right\|+L\left\|v_{n}\right\|\right\} \leqslant \widehat{M}$ for some $\widehat{M}>0$. Also it is not difficult to derive that

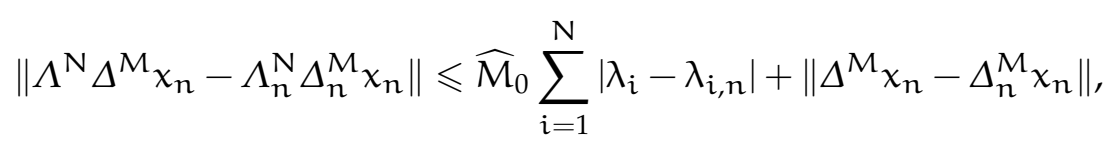

where $\sup _{n \geqslant 0}\left\{\sum_{i=1}^{N}\left\|A_{i} \Lambda^{i-1} \Delta^{M} x_{n}\right\|\right\} \leqslant \widehat{M}_{0}$ for some $\widehat{M}_{0}>0$. Observe that

$$
\left\|\Delta^{M} x_{n}-\Delta_{n}^{M} x_{n}\right\| \leqslant \widehat{M}_{1} \sum_{j=1}^{M}\left|r_{j}-r_{j, n}\right|,
$$

where $\sup _{n \geqslant 0}\left\{\sum_{j=1}^{M}\left[\left\|B_{j} \Delta^{j-1} x_{n}\right\|+\frac{1}{r_{j}}\left\|T_{r_{j}}^{\left(\Theta_{j}, \varphi_{j}\right)}\left(I-r_{j} B_{j}\right) \Delta^{j-1} x_{n}-\left(I-r_{j} B_{j}\right) \Delta^{j-1} x_{n}\right\|\right]\right\} \leqslant \widehat{M}_{1}$ for some $\widehat{M}_{1}>$ 0 . In terms of (3.8), (3.9), (3.10) we calculate

$$
\begin{aligned}
& \left\|\mathrm{T} \Lambda^{\mathrm{N}} \Delta^{\mathrm{M}}{\chi_{n}}_{n}-\mathrm{T}_{n} \Lambda_{n}^{\mathrm{N}} \Delta_{n}^{\mathrm{M}} \mathrm{x}_{\mathrm{n}}\right\| \leqslant\left\|\Lambda^{\mathrm{N}} \Delta^{\mathrm{M}}{\chi_{n}}_{n}-\Lambda_{n}^{\mathrm{N}} \Delta_{n}^{\mathrm{M}} \mathrm{x}_{\mathrm{n}}\right\|+\widehat{\mathrm{M}}\left|\frac{2}{\mathrm{~L}}-\lambda_{n}\right| \\
& \leqslant\left\|\Delta^{M} x_{n}-\Delta_{n}^{M} x_{n}\right\|+\widehat{M}_{0} \sum_{i=1}^{N}\left|\lambda_{i}-\lambda_{i, n}\right|+\widehat{M}\left|\frac{2}{L}-\lambda_{n}\right| \\
& \leqslant \widehat{M}_{1} \sum_{j=1}^{M}\left|r_{j}-r_{j, n}\right|+\widehat{M}_{0} \sum_{i=1}^{N}\left|\lambda_{i}-\lambda_{i, n}\right|+\widehat{M}\left|\frac{2}{L}-\lambda_{n}\right| .
\end{aligned}
$$

Consequently, it is not hard to find that

$$
\begin{aligned}
& \left\|\mathrm{T} \Lambda^{\mathrm{N}} \Delta^{\mathrm{M}} \mathrm{x}_{\mathrm{t}}-\mathrm{x}_{\mathrm{n}+1}\right\| \leqslant\left\|\mathrm{T} \Lambda^{\mathrm{N}} \Delta^{\mathrm{M}} \mathrm{x}_{\mathrm{t}}-\mathrm{T} \Lambda^{\mathrm{N}} \Delta^{\mathrm{M}} \mathrm{x}_{\mathrm{n}}\right\| \\
& +\left\|\mathrm{T} \Lambda^{\mathrm{N}} \Delta^{\mathrm{M}}{x_{n}}_{n}-\mathrm{T}_{\mathrm{n}} \Lambda_{\mathrm{n}}^{\mathrm{N}} \Delta_{\mathrm{n}}^{\mathrm{M}} \mathrm{x}_{\mathrm{n}}\right\|+\left\|\mathrm{T}_{\mathrm{n}} \Lambda_{\mathrm{n}}^{\mathrm{N}} \Delta_{n}^{\mathrm{M}} \mathrm{x}_{\mathrm{n}}-\mathrm{x}_{\mathrm{n}+1}\right\| \\
& \leqslant\left\|x_{t}-x_{n}\right\|+\widehat{M}_{1} \sum_{j=1}^{M}\left|r_{j}-r_{j, n}\right|+\widehat{M}_{0} \sum_{i=1}^{N}\left|\lambda_{i}-\lambda_{i, n}\right| \\
& +\widehat{\mathrm{M}}\left|\frac{2}{\mathrm{~L}}-\lambda_{\mathrm{n}}\right|+|| \mathrm{T}_{\mathrm{n}} v_{\mathrm{n}}-x_{\mathrm{n}+1} \| \\
& =\left\|x_{t}-x_{n}\right\|+\epsilon_{n} \text {, }
\end{aligned}
$$

where $\epsilon_{n}=\widehat{M}_{1} \sum_{j=1}^{M}\left|r_{j}-r_{j, n}\right|+\widehat{M}_{0} \sum_{i=1}^{N}\left|\lambda_{i}-\lambda_{i, n}\right|+\widehat{M}\left|\frac{2}{L}-\lambda_{n}\right|+\left\|T_{n} v_{n}-x_{n+1}\right\| \rightarrow 0$ as $n \rightarrow \infty$. Also observing that $A$ is strongly positive, we have

$$
\left\langle A x_{t}-A x_{n}, x_{t}-x_{n}\right\rangle=\left\langle A\left(x_{t}-x_{n}\right), x_{t}-x_{n}\right\rangle \geqslant \bar{\gamma}\left\|x_{t}-x_{n}\right\|^{2} .
$$

For simplicity, we write $w_{t}=\left(I-s_{t} A\right) T \Lambda^{N} \Delta^{M} x_{t}+s_{t}\left(t \gamma V x_{t}+(I-t \mu F) T \Lambda^{N} \Delta^{M} x_{t}\right)$. Then we obtain that $x_{\mathrm{t}}=\mathrm{P}_{\mathrm{C}} w_{\mathrm{t}}$ and 


$$
\begin{aligned}
x_{t}-x_{n+1}= & x_{t}-w_{t}+\left(I-s_{t} A\right) T \Lambda^{N} \Delta^{M} x_{t}+s_{t}\left(t \gamma V x_{t}+(I-t \mu F) T \Lambda^{N} \Delta^{M} x_{t}\right)-x_{n+1} \\
= & \left(I-s_{t} A\right) T \Lambda^{N} \Delta^{M} x_{t}-\left(I-s_{t} A\right) x_{n+1}+s_{t}\left(t \gamma V x_{t}+(I-t \mu F) T \Lambda^{N} \Delta^{M} x_{t}-A x_{n+1}\right) \\
& +x_{t}-w_{t}
\end{aligned}
$$

Applying Lemma 2.7, we have

$$
\begin{aligned}
\left\|x_{t}-x_{n+1}\right\|^{2} \leqslant & \left\|\left(I-s_{t} A\right) T \Lambda^{N} \Delta^{M} x_{t}-\left(I-s_{t} A\right) x_{n+1}\right\|^{2} \\
& +2 s_{t}\left\langle T \Lambda^{N} \Delta^{M} x_{t}-t\left(\mu F T \Lambda^{N} \Delta^{M} x_{t}\right.\right. \\
& \left.\left.-\gamma V x_{t}\right)-A x_{n+1}, x_{t}-x_{n+1}\right\rangle+2\left\langle x_{t}-w_{t}, x_{t}-x_{n+1}\right\rangle \\
\leqslant & \left\|\left(I-s_{t} A\right) T \Lambda^{N} \Delta^{M} x_{t}-\left(I-s_{t} A\right) x_{n+1}\right\|^{2} \\
& +2 s_{t}\left\langle T \Lambda^{N} \Delta^{M} x_{t}-t\left(\mu F T \Lambda^{N} \Delta^{M} x_{t}-\gamma V x_{t}\right)-A x_{n+1}, x_{t}-x_{n+1}\right\rangle \\
\leqslant & \left(1-s_{t} \bar{\gamma}\right)^{2}\left\|T \Lambda^{N} \Delta^{M} x_{t}-x_{n+1}\right\|^{2}+2 s_{t}\left\langle T \Lambda^{N} \Delta^{M} x_{t}-x_{t}, x_{t}-x_{n+1}\right\rangle \\
& -2 s_{t} t\left\langle\mu F T \Lambda^{N} \Delta^{M} x_{t}-\gamma V x_{t}, x_{t}-x_{n+1}\right\rangle+2 s_{t}\left\langle x_{t}-A x_{n+1}, x_{t}-x_{n+1}\right\rangle .
\end{aligned}
$$

By using (3.11) and (3.12) in (3.13), we obtain

$$
\begin{aligned}
& \left\|x_{t}-x_{n+1}\right\|^{2} \leqslant\left(1-s_{t} \bar{\gamma}\right)^{2}\left\|T \Lambda^{N} \Delta^{M} x_{t}-x_{n+1}\right\|^{2}+2 s_{t}\left\langle T \Lambda^{N} \Delta^{M} x_{t}-x_{t}, x_{t}-x_{n+1}\right\rangle
\end{aligned}
$$

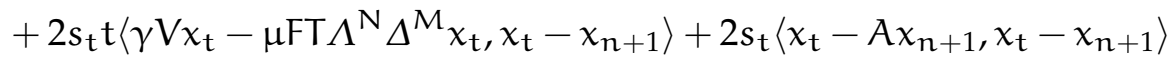

$$
\begin{aligned}
& \leqslant\left(1-s_{\mathrm{t}} \bar{\gamma}\right)^{2}\left(\left\|x_{\mathrm{t}}-x_{\mathrm{n}}\right\|+\epsilon_{\mathrm{n}}\right)^{2}+2 s_{\mathrm{t}}\left\|\mathrm{T} \Lambda^{\mathrm{N}} \Delta^{\mathrm{M}} x_{\mathrm{t}}-x_{\mathrm{t}}\right\|\left\|x_{\mathrm{t}}-x_{\mathrm{n}+1}\right\| \\
& +2 s_{\mathrm{t}} \mathrm{t}\left\|\gamma \mathrm{V} \mathrm{x}_{\mathrm{t}}-\mu \mathrm{FT} \Lambda^{\mathrm{N}} \Delta^{\mathrm{M}} \mathrm{x}_{\mathrm{t}}\right\|\left\|x_{\mathrm{t}}-\mathrm{x}_{\mathrm{n}+1}\right\|+2 s_{\mathrm{t}}\left\langle\mathrm{x}_{\mathrm{t}}-\mathrm{A} x_{\mathrm{n}+1}, \mathrm{x}_{\mathrm{t}}-\mathrm{x}_{\mathrm{n}+1}\right\rangle \\
& =\left(s_{t}^{2} \bar{\gamma}-2 s_{t}\right) \bar{\gamma}\left\|x_{t}-x_{n}\right\|^{2}+\left\|x_{t}-x_{n}\right\|^{2} \\
& +\left(1-s_{\mathrm{t}} \bar{\gamma}\right)^{2}\left[2\left\|x_{\mathrm{t}}-x_{\mathrm{n}}\right\| \epsilon_{\mathrm{n}}+\epsilon_{\mathrm{n}}^{2}\right]+2 s_{\mathrm{t}}\left\|\mathrm{T} \Lambda^{\mathrm{N}} \Delta^{\mathrm{M}} x_{\mathrm{t}}-x_{\mathrm{t}}\right\|\left\|x_{\mathrm{t}}-x_{\mathrm{n}+1}\right\| \\
& +2 s_{\mathrm{t}} \mathrm{t}\left\|\gamma \mathrm{V} \mathrm{x}_{\mathrm{t}}-\mu \mathrm{FT} \Lambda^{\mathrm{N}} \Delta^{\mathrm{M}} \mathrm{x}_{\mathrm{t}}\right\|\left\|\mathrm{x}_{\mathrm{t}}-\mathrm{x}_{\mathrm{n}+1}\right\|+2 s_{\mathrm{t}}\left\langle\mathrm{x}_{\mathrm{t}}-\mathrm{A} \mathrm{x}_{\mathrm{n}+1}, \mathrm{x}_{\mathrm{t}}-\mathrm{x}_{\mathrm{n}+1}\right\rangle \\
& =\left(s_{\mathrm{t}}^{2} \bar{\gamma}-2 s_{\mathrm{t}}\right) \bar{\gamma}\left\|x_{\mathrm{t}}-x_{\mathrm{n}}\right\|^{2}+\left\|x_{\mathrm{t}}-x_{\mathrm{n}}\right\|^{2}+\left(1-s_{\mathrm{t}} \bar{\gamma}\right)^{2}\left[2\left\|x_{\mathrm{t}}-x_{\mathrm{n}}\right\| \epsilon_{\mathrm{n}}+\epsilon_{\mathrm{n}}^{2}\right]
\end{aligned}
$$

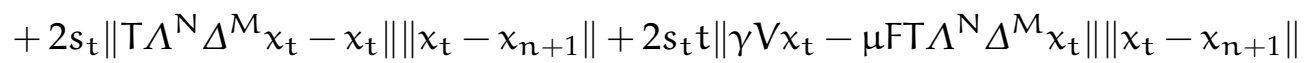

$$
\begin{aligned}
& +2 s_{\mathrm{t}}\left\langle x_{\mathrm{t}}-A x_{n+1}, x_{\mathrm{t}}-x_{n+1}\right\rangle \\
& \leqslant\left(s_{t}^{2} \bar{\gamma}-2 s_{t}\right)\left\langle A x_{t}-A x_{n}, x_{t}-x_{n}\right\rangle+\left\|x_{t}-x_{n}\right\|^{2}+\left(1-s_{t} \bar{\gamma}\right)^{2}\left[2\left\|x_{t}-x_{n}\right\| \epsilon_{n}+\epsilon_{n}^{2}\right] \\
& +2 s_{\mathrm{t}}\left\|\mathrm{T} \Lambda^{\mathrm{N}} \Delta^{\mathrm{M}} \mathrm{x}_{\mathrm{t}}-\mathrm{x}_{\mathrm{t}}\right\|\left\|\mathrm{x}_{\mathrm{t}}-\mathrm{x}_{\mathrm{n}+1}\right\|+2 s_{\mathrm{t}} \mathrm{t}\left\|\gamma \mathrm{V} \mathrm{x}_{\mathrm{t}}-\mu \mathrm{FT} \Lambda^{\mathrm{N}} \Delta^{\mathrm{M}} \chi_{\mathrm{t}}\right\|\left\|\mathrm{x}_{\mathrm{t}}-\mathrm{x}_{\mathrm{n}+1}\right\| \\
& +2 s_{\mathrm{t}}\left\langle x_{\mathrm{t}}-A x_{\mathrm{n}+1}, x_{\mathrm{t}}-x_{\mathrm{n}+1}\right\rangle \\
& =s_{t}^{2} \bar{\gamma}\left\langle A x_{t}-A x_{n}, x_{t}-x_{n}\right\rangle+\left\|x_{t}-x_{n}\right\|^{2}+\left(1-s_{t} \bar{\gamma}\right)^{2}\left[2\left\|x_{t}-x_{n}\right\| \epsilon_{n}+\epsilon_{n}^{2}\right]
\end{aligned}
$$

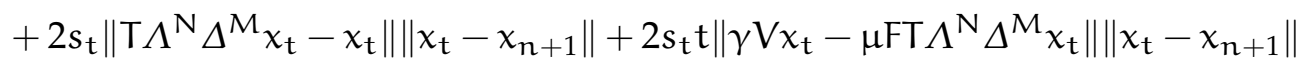

$$
\begin{aligned}
& +2 s_{t}\left[\left\langle x_{t}-A x_{n+1}, x_{t}-x_{n+1}\right\rangle-\left\langle A x_{t}-A x_{n}, x_{t}-x_{n}\right\rangle\right] \\
& =s_{t}^{2} \bar{\gamma}\left\langle A\left(x_{t}-x_{n}\right), x_{t}-x_{n}\right\rangle+\left\|x_{t}-x_{n}\right\|^{2}+\left(1-s_{t} \bar{\gamma}\right)^{2}\left[2\left\|x_{t}-x_{n}\right\| \epsilon_{n}+\epsilon_{n}^{2}\right]
\end{aligned}
$$

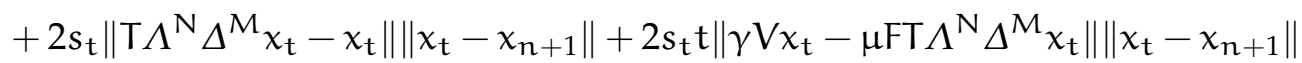

$$
\begin{aligned}
& +2 s_{t}\left[\left\langle(I-A) x_{t}, x_{t}-x_{n+1}\right\rangle+\left\langle A\left(x_{t}-x_{n+1}\right), x_{t}-x_{n+1}\right\rangle-\left\langle A\left(x_{t}-x_{n}\right), x_{t}-x_{n}\right\rangle\right] \text {. }
\end{aligned}
$$

Applying the Banach limit LIM to (3.14), from $\epsilon_{n} \rightarrow 0$ we have

$$
\begin{aligned}
\operatorname{LIM}_{n}\left\|x_{t}-x_{n+1}\right\|^{2} \leqslant & s_{t}^{2} \bar{\gamma} \operatorname{LIM}_{n}\left\langle A\left(x_{t}-x_{n}\right), x_{t}-x_{n}\right\rangle+\operatorname{LIM}_{n}\left\|x_{t}-x_{n}\right\|^{2} \\
& +2 s_{t}\left\|\operatorname{T} \Lambda^{N} \Delta^{M} x_{t}-x_{t}\right\| \operatorname{LIM}_{n}\left\|x_{t}-x_{n+1}\right\|+2 s_{t} t \| \gamma V x_{t} \\
& -\mu F T \Lambda^{N} \Delta^{M} x_{t}\left\|\operatorname{LIM}_{n}\right\| x_{t}-x_{n+1} \| \\
& +2 s_{t}\left[\operatorname{LIM}_{n}\left\langle(I-A) x_{t}, x_{t}-x_{n+1}\right\rangle+\operatorname{LIM}_{n}\left\langle A\left(x_{t}-x_{n+1}\right), x_{t}-x_{n+1}\right\rangle\right. \\
& \left.-\operatorname{LIM}_{n}\left\langle A\left(x_{t}-x_{n}\right), x_{t}-x_{n}\right\rangle\right] .
\end{aligned}
$$


Utilizing the property $\operatorname{LIM}_{n} a_{n}=\operatorname{LIM}_{n} a_{n+1}$ of the Banach limit in (3.15), we obtain

$$
\begin{aligned}
\operatorname{LIM}_{n}\left\langle(A-I) x_{t}, x_{t}-x_{n}\right\rangle= & \operatorname{LIM}_{n}\left\langle(A-I) x_{t}, x_{t}-x_{n+1}\right\rangle \\
\leqslant & \frac{s_{t} \bar{\gamma}}{2} \operatorname{LIM}_{n}\left\langle A\left(x_{t}-x_{n}\right), x_{t}-x_{n}\right\rangle \\
& +\frac{1}{2 s_{t}}\left[\operatorname{LIM}_{n}\left\|x_{t}-x_{n}\right\|^{2}-\operatorname{LIM}_{n}\left\|x_{t}-x_{n+1}\right\|^{2}\right] \\
& +\left\|\operatorname{T} \Lambda^{N} \Delta^{M} x_{t}-x_{t}\right\| \operatorname{LIM}_{n}\left\|x_{t}-x_{n}\right\| \\
& +t\left\|\gamma \operatorname{tr} x_{t}-\mu F T \Lambda^{N} \Delta^{M} x_{t}\right\| \operatorname{LIM}_{n}\left\|x_{t}-x_{n}\right\| \\
& +\operatorname{LIM}_{n}\left\langle A\left(x_{t}-x_{n+1}\right), x_{t}-x_{n+1}\right\rangle-\operatorname{LIM}_{n}\left\langle A\left(x_{t}-x_{n}\right), x_{t}-x_{n}\right\rangle \\
\leqslant & \frac{s_{t} \bar{\gamma}}{2} \operatorname{LIM}_{n}\left\langle A\left(x_{t}-x_{n}\right), x_{t}-x_{n}\right\rangle+\left\|\operatorname{T} \Lambda^{N} \Delta^{M} x_{t}-x_{t}\right\| \operatorname{LIM}_{n}\left\|x_{t}-x_{n}\right\| \\
& +t\|\gamma \operatorname{t}\| x_{t}-\mu F T \Lambda^{N} \Delta^{M} x_{t}\left\|\operatorname{LIM}_{n}\right\| x_{t}-x_{n} \| .
\end{aligned}
$$

Since as $t \rightarrow 0$,

$$
s_{t}\left\langle A\left(x_{t}-x_{n}\right), x_{t}-x_{n}\right\rangle \leqslant s_{t}\|A\|\left\|x_{t}-x_{n}\right\|^{2} \leqslant s_{t} K \rightarrow 0,
$$

where $\|A\|\left\|x_{t}-x_{n}\right\|^{2} \leqslant K$,

$$
\left\|\mathrm{T} \Lambda^{\mathrm{N}} \Delta^{\mathrm{M}} \mathrm{x}_{\mathrm{t}}-\mathrm{x}_{\mathrm{t}}\right\| \rightarrow 0, \quad \text { and } \mathrm{t}\left\|\gamma \mathrm{V} \mathrm{x}_{\mathrm{t}}-\mu \mathrm{FT} \Lambda^{\mathrm{N}} \Delta^{\mathrm{M}} \mathrm{x}_{\mathrm{t}}\right\| \rightarrow 0 \quad \text { as } \mathrm{t} \rightarrow 0,
$$

we conclude from (3.16), (3.17), (3.18) that

$$
\begin{aligned}
& \operatorname{LIM}_{n}\left\langle(A-I) \tilde{x}, \tilde{x}-x_{n}\right\rangle \leqslant \operatorname{limsupLIM}_{n \rightarrow 0}\left\langle(A-I) x_{t}, x_{t}-x_{n}\right\rangle \\
& \leqslant \limsup _{t \rightarrow 0} \frac{s_{t} \bar{\gamma}}{2} \operatorname{LIM}_{n}\left\langle A\left(x_{t}-x_{n}\right), x_{t}-x_{n}\right\rangle \\
& +\limsup _{\mathrm{t} \rightarrow 0}\left\|\mathrm{~T} \Lambda^{\mathrm{N}} \Delta^{\mathrm{M}} \mathrm{x}_{\mathrm{t}}-\mathrm{x}_{\mathrm{t}}\right\| \operatorname{LIM}_{\mathrm{n}}\left\|\mathrm{x}_{\mathrm{t}}-\mathrm{x}_{\mathrm{n}}\right\| \\
& +\underset{t \rightarrow 0}{\operatorname{limsupt}}\left\|\gamma \mathrm{V} x_{t}-\mu \mathrm{FT} \Lambda^{\mathrm{N}} \Delta^{\mathrm{M}} x_{\mathrm{t}}\right\| \operatorname{LIM}_{n}\left\|x_{\mathrm{t}}-x_{\mathrm{n}}\right\| \\
& =0 \text {. }
\end{aligned}
$$

This completes the proof.

Now, using Theorem 3.3 we can establish the following strong convergence of the sequence $\left\{x_{n}\right\}$ generated by the multistep relaxed explicit extragradient-like scheme (3.3) to a point $\tilde{x} \in \Omega$, which is also the unique solution of the VIP (3.2) whose proof is omitted.

Theorem 3.4. Let $\left\{x_{n}\right\}$ be the sequence generated by the explicit scheme (3.3), where $\left\{\alpha_{n}\right\}$ and $\left\{s_{n}\right\}$ satisfy the following conditions:

(C1) $\left\{\alpha_{n}\right\} \subset[0,1],\left\{s_{n}\right\} \subset\left(0, \frac{1}{2}\right)$ and $\alpha_{n} \rightarrow 0, s_{n} \rightarrow 0$ as $n \rightarrow \infty$;

(C2) $\sum_{\mathfrak{n}=0}^{\infty} s_{\mathfrak{n}}=\infty$.

If $\left\{x_{n}\right\}$ is weakly asymptotically regular (i.e., $x_{n+1}-x_{n} \rightarrow 0$ ), then $x_{n}$ converges strongly to a point $\tilde{x} \in \Omega$, which is the unique solution of the VIP (3.2).

\section{Acknowledgment}

This work was supported by the Innovation Program of Shanghai Municipal Education Commission (15ZZ068), Ph.D. Program Foundation of Ministry of Education of China (20123127110002) and Program for Shanghai Outstanding Academic Leaders in Shanghai City (15XD1503100). This study was supported by the grant MOST 105-2115-M-037-001, and the grand from Research Center for Nonlinear Analysis and Optimization, Kaohsiung Medical University, Kaohsiung, Taiwan. 


\section{References}

[1] A. E. Al-Mazrooei, B. A. Bin Dehaish, A. Latif, J.-C. Yao, On general system of variational inequalities in Banach spaces, J. Nonlinear Convex Anal., 16 (2015), 639-658. 1

[2] A. S. M. Alofi, A. Latif, A. E. Al-Mazrooei, J.-C. Yao, Composite viscosity iterative methods for general systems of variational inequalities and fixed point problem in Hilbert spaces, J. Nonlinear Convex Anal., 17 (2016), 669-682.

[3] A. Bnouhachem, Q. H. Ansari, J.-C. Yao, Strong convergence algorithm for hierarchical fixed point problems of a finite family of nonexpansive mappings, Fixed Point Theory, 17 (2016), 47-62. 1

[4] C. Byrne, A unified treatment of some iterative algorithms in signal processing and image reconstruction, Inverse Problems, 20 (2004), 103-120. 2.6

[5] L.-C. Ceng, Q. H. Ansari, A. Petruşel, J.-C. Yao, Approximation methods for triple hierarchical variational inequalities (I), Fixed Point Theory, 16 (2015), 67-90. 1

[6] L.-C. Ceng, Q. H. Ansari, A. Petruşel, J.-C. Yao, Approximation methods for triple hierarchical variational inequalities (II)., Fixed Point Theory, 16 (2015), 237-259. 1

[7] L.-C. Ceng, Q. H. Ansari, S. Schaible, Hybrid extragradient-like methods for generalized mixed equilibrium problems, systems of generalized equilibrium problems and optimization problems, J. Global Optim., 53 (2012), 69-96. 1

[8] L.-C. Ceng, Q. H. Ansari, S. Schaible, J.-C. Yao, Iterative methods for generalized equilibrium problems, systems of general generalized equilibrium problems and fixed point problems for nonexpansive mappings in Hilbert spaces, Fixed Point Theory, 12 (2011), 293-308. 1

[9] L.-C. Ceng, Q. H. Ansari, M.-M. Wong, J.-C. Yao, Mann type hybrid extragradient method for variational inequalities, variational inclusions and fixed point problems, Fixed Point Theory, 13 (2012), 403-422. 1

[10] L.-C. Ceng, S.-M. Guu, J.-C. Yao, A general composite iterative algorithm for nonexpansive mappings in Hilbert spaces, Comput. Math. Appl., 61 (2011), 2447-2455. 3

[11] L.-C. Ceng, S.-M. Guu, J.-C. Yao, Finding common solutions of a variational inequality, a general system of variational inequalities, and a fixed-point problem via a hybrid extragradient method, Fixed Point Theory Appl., 2011 (2011), 22 pages. 1

[12] L.-C. Ceng, S. Plubtieng, M.-M. Wong, J.-C. Yao, System of variational inequalities with constraints of mixed equilibria, variational inequalities, and convex minimization and fixed point problems, J. Nonlinear Convex Anal., 16 (2015), 385421. 1

[13] L.-C. Ceng, C.-F. Wen, C. Liou, Multi-step iterative algorithms with regularization for triple hierarchical variational inequalities with constraints of mixed equilibria, variational inclusions, and convex minimization, J. Inequal. Appl., 2014 (2014), 47 pages. 1

[14] L.-C. Ceng, J.-C. Yao, A hybrid iterative scheme for mixed equilibrium problems and fixed point problems, J. Comput. Appl. Math., 214 (2008), 186-201. 1, 2.4

[15] L.-C. Ceng, J.-C. Yao, A relaxed extragradient-like method for a generalized mixed equilibrium problem, a general system of generalized equilibria and a fixed point problem, Nonlinear Anal., 72 (2010), 1922-1937. 1

[16] S. Y. Cho, W.-L. Li, S. M. Kang, Convergence analysis of an iterative algorithm for monotone operators, J. Inequal. Appl., 2013 (2013), 14 pages. 1

[17] K. Goebel, W. A. Kirk, Topics in metric fixed point theory, Cambridge Studies in Advanced Mathematics, Cambridge University Press, Cambridge, (1990). 2.11

[18] G. M. Korpelevič, An extragradient method for finding saddle points and for other problems, (Russian) Ékonom. i Mat. Metody, 12 (1976), 747-756. 1

[19] G. Marino, H.-K. Xu, A general iterative method for nonexpansive mappings in Hilbert spaces, J. Math. Anal. Appl., 318 (2006), 43-56. 2.15

[20] G. Marino, H.-K. Xu, Weak and strong convergence theorems for strict pseudo-contractions in Hilbert spaces, J. Math. Anal. Appl., 329 (2007), 336-346. 2.9

[21] J.-W. Peng, J.-C. Yao, A new hybrid-extragradient method for generalized mixed equilibrium problems, fixed point problems and variational inequality problems, Taiwanese J. Math., 12 (2008), 1401-1432. 1, 1

[22] R. T. Rockafellar, Monotone operators and the proximal point algorithm, SIAM J. Control Optimization, 14 (1976), 877-898. 2

[23] N. Shioji, W. Takahashi, Strong convergence of approximated sequences for nonexpansive mappings in Banach spaces, Proc. Amer. Math. Soc., 125 (1997), 3641-3645. 2

[24] H.-K. Xu, Iterative algorithms for nonlinear operators, J. London Math. Soc., 66 (2002), 240-256. 2.14

[25] H.-K. Xu, T.-H. Kim, Convergence of hybrid steepest-descent methods for variational inequalities, J. Optim. Theory Appl., 119 (2003), 185-201. 2.13

[26] Y.-H. Yao, Y.-C. Liou, S. M. Kang, Approach to common elements of variational inequality problems and fixed point problems via a relaxed extragradient method, Comput. Math. Appl., 59 (2010), 3472-3480. 2.10

[27] L.-C. Zeng, J.-C. Yao, Modified combined relaxation method for general monotone equilibrium problems in Hilbert spaces, J. Optim. Theory Appl., 131 (2006), 469-483. 1 